\title{
Effects of different mycotoxins on humans, cell genome and their involvement in cancer (Review)
}

\author{
MOWAFFAQ ADAM AHMED ADAM, YASSER M. TABANA, KHIRUN BINTI MUSA and DOBLIN ANAK SANDAI \\ Infectomics Cluster, Advanced Medical and Dental Institute, Universiti Sains Malaysia, Penang, Malaysia
}

Received August 19, 2016; Accepted January 16, 2017

DOI: $10.3892 /$ or.2017.5424

\begin{abstract}
The chemical nature of most of the mycotoxins makes them highly liposoluble compounds that can be absorbed from the site of exposure such as from the gastrointestinal and respiratory tract to the blood stream where it can be dissimilated throughout the body and reach different organs such as the liver and kidneys. Mycotoxins have a strong tendency and ability to penetrate the human and animal cells and reach the cellular genome where it causes a major mutagenic change in the nucleotide sequence which leads to strong and permanent defects in the genome. This defect will eventually be transcribed, translated and lead to the development of cancer. In this review, the chemical and physical nature of mycotoxins, the action of mycotoxins on the cellular genome and its effect on humans, mycotoxins and their carcinogenicity and mycotoxins research gaps are discussed, and new research areas are suggested. The research review posed various questions. What are the different mycotoxins that can cause cancer, what is the role of mycotoxins in causing cancer and what types of cancers can be caused by mycotoxins? These questions have been selected due to the significant increase in the mycotoxin contamination and the cancer incidence rate in the contemporary world. By revealing and understanding the role of mycotoxins in developing cancer, measures to reduce the risks and incidents of cancer could be taken.
\end{abstract}

\section{Contents}

1. Introduction

2. Types of mycotoxins and their natural commodities

3. The chemical and physical nature of mycotoxins

Correspondence to: Dr Doblin Anak Sandai, Infectomics Cluster, Advanced Medical and Dental Institute, Universiti Sains Malaysia, 13200 Kepala Batas, Penang, Malaysia

E-mail: doblin@usm.my

Abbreviations: TLC, thin-layer chromatography; HCC, hepatocellular carcinoma

Key words: mycotoxins, cancer, aflatoxins
4. The action of mycotoxins on the cellular genome and its effect on humans

5. Mycotoxins and their carcinogenicity

6. Mycotoxin research gaps and the recommended new research areas

7. Conclusions

\section{Introduction}

Many chemical mutagens were proven to cause mutation and inactivation of the cancer suppressor genes such as P53, BRCA1 and BRCA2. One of the most influential chemical compounds that could cause a mutation in these genes are the mycotoxins (1). Mycotoxins are carcinogenic toxins that are produced by many Aspergillus and Penicillium species growing on food commodities (1). Among the different mycotoxins, aflatoxin $\mathrm{B} 1$ has been reported as the highest carcinogenic mycotoxin (2) and aflatoxin B1 can penetrate the cell membrane and attach to its DNA where it causes irreversible mutations (2). The chemical nature of aflatoxins makes it a highly liposoluble compound that can be absorbed from the site of exposure such as from the gastrointestinal and respiratory tract to the blood stream where it can move throughout the body (3). The exposure to these carcinogenic mycotoxins can be through the ingestion of the contaminated food that ends up in the stomach where it gets absorbed or by inhaling the dust particles of aflatoxins B1 from the food that is contaminated with these aflatoxins (3). Once the aflatoxins enter the cells, they are metabolized by the action of cytochrome P450, a microsomal enzyme to aflatoxin-8, 9-epoxide in the detoxification metabolic pathway for aflatoxins. It is highly reactive and unstable and requires the binding to a DNA or to the protein molecule in order to become more stable (3). Once the highly unstable aflatoxin-8, 9-epoxide binds to the DNA molecule with high affinity, it forms aflatoxin-N7-guanine that cause a guanine $(\mathrm{G})$ to thymine $(\mathrm{T})$ transversion mutations which will directly affect the cell cycle by affecting the P53 gene which carries the codes for tumor suppressor proteins, meant to inhibit the development of tumors and cancers (3).

The role of aflatoxin B1 in causing mutation in the humans genome was extensively studied (2), many other mycotoxins are yet to be investigated to understand their method of action once they are in contact with the humans genome. This is particularly crucial because many mycotoxins have a closely 
related chemical composition and similar functions inside the human body. The researchers decided on two research questions in this review that accurately describe the objectives of this research: What are the different types of mycotoxins that can cause cancer? What is the role of mycotoxins in causing cancer and what types of cancers can be caused by mycotoxins?

The reason for this review is due to the fact that there is an increase in mycotoxin contamination in the world and by understanding the role of different mycotoxins in the human body and their levels of toxicity and carcinogenicity, many new measures could be followed and many human lives and animals alike could be saved. In addition, there is a gap in cancer studies relating to mycotoxins as it has been only related to liver cancer (4). Although due to the similarity in nature and functions, mycotoxins can be related to many types of cancer. This review will concentrate on the previously published studies that answer both of our research questions and build on the arguments that support these questions.

\section{Types of mycotoxins and their natural commodities}

In an experiment done by El-Banna et al (5) nearly 1400 Penicillium isolates were collected from several cultures, isolated directly from food and feed. Each isolate was identified using Pitt's classification to investigate their mycotoxins production, and 18 different mycotoxins were isolated. Each isolate was allowed to grow on malt extract agar medium and was incubated for the period between one to three weeks at $25^{\circ} \mathrm{C}$. The mycotoxins were then extracted using chloroform and filtration, and the produced mycotoxins were concentrated. Finally, the mycotoxins were classified and characterized by mycotoxins analysis using TLC (6-8). This experiment resulted in the production and the identification of 18 different mycotoxins from one or more species of Penicillium. The toxins are as follows: Brevianamid A produced by 3 species, Citreoviridin produced by 2 species, Citrinin (Fig. 2) produced by 3 species, Cyclopiazonic acid produced by 8 species, Fumitremorgin B produced by 1 species, Griseofulvin produced by 6 species, luteoskyrin produced by 1 species, Ochratoxin A produced by 2 species, Patulin produced by 4 species, Penicillic acid produced by 2 species, Penitrem A produced by 1 species, PR-toxin produced by 1 species, Roquefortine produced by 2 species, rugulosin produced by 2 species, Verrucosidin produced by 1 species, Verruculogen produced by 1 species, Viridicarumtoxin produced by produced by 2 species and finally, Xanthomegnin produced by 2 species (5).

Another group of mycotoxins is produced by Aspergillus species, and these mycotoxins are called Aflatoxins (12). They were found to be extremely toxic and highly cariogenic. Aflatoxins are chemical compounds that are released by the fungi Asergillus Flavus and Aspergillus Parasiticus as secondary metabolites, and the different laboratory investigations confirmed the high carcinogenicity of these chemical compounds and how they are associated with many cancers such as liver and kidney (9-12). The different types of aflatoxins include aflatoxin B1 and B2, produced by Aspergillus Flavus and Aspergillus parasiticus, Aflatoxin G1 and G2, produced by Aspergillus parasiticus (13-16). Among these toxins, it was found the B1 and G1 are the most toxic with the<smiles>COc1cc2c(c3oc(=O)c4c(c13)CCC4=O)[C@H]1C=CO[C@@H]1O2</smiles>

Figure 1. Chemical structure of Aflatoxin B1.<smiles>CC1=C2C(=CO[C@@H](C)[C@@H]2C)C(O)=C(C(=O)O)C1=O</smiles>

Figure 2. Chemical structure of Citrinin.

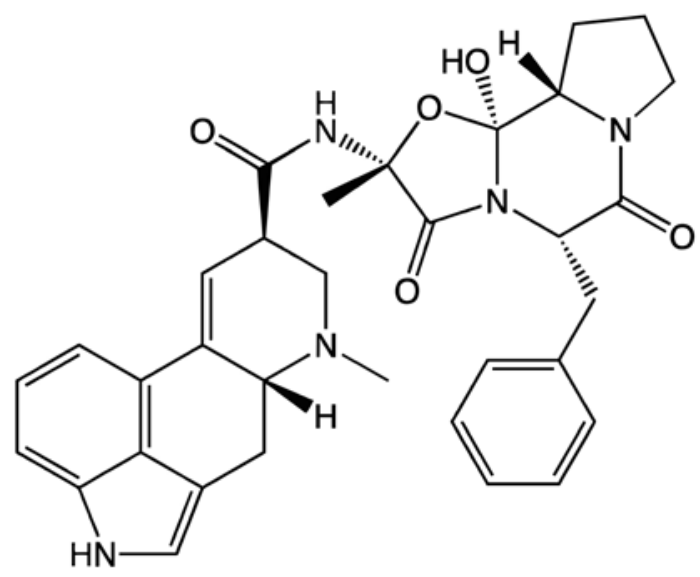

Figure 3. Chemical structure of Ergotamine.

highest carcinogenic effect on animal cells (9). Food products that can be contaminated with aflatoxins include cereal (maize, sorghum, pearl millet, rice, and wheat), oil seeds (groundnut, soybean, sunflower, and cotton), spices (chilies, black pepper, coriander, turmeric, and ginger), tree nuts (almonds, pistachio, walnuts, and coconut) and milk (17-22). Moreover, aflatoxins are found in the contaminated tobacco leaves (23). Aflatoxins can also be present in the dry soil, which can move through underground water with rain and be ingested by humans and animals through drinking water (24).

Another group of mycotoxins that is produced by Aspergillus, Penicillium and Fusarium were classified and characterized based on the frequency of their accordance with nature and their severity of the diseases they cause. These mycotoxins are Deoxynivalenol (Fig. 8), Fumonisins (Fig. 4), Zearalenone (Fig. 10), T-2 toxin (Fig. 7), and finally certain types of ergot alkaloids. Found mainly on grain crops (29-31), they were known to develop a set of diseases called Mycotoxicoses, and these diseases include blood toxicity, food poisoning and sometimes cancer (25-27). 


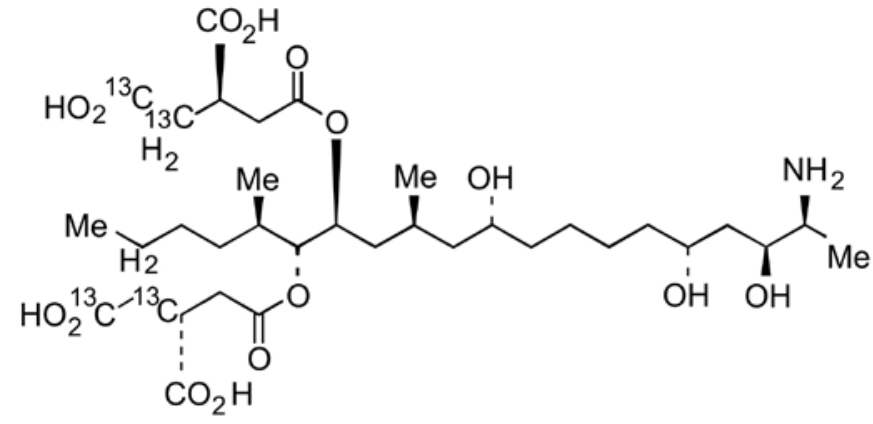

Figure 4. Chemical structure of Fumonisin B1.<smiles>C[C@H]1Cc2c(Cl)cc(C(=O)N[C@@H](Cc3ccccc3)C(=O)O)c(O)c2C(=O)O1</smiles>

Figure 5. Chemical structure of Ochratoxin A.

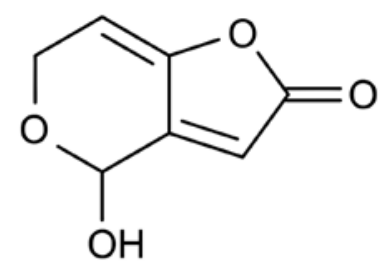

Figure 6. Chemical structure of Patulin.

Another group of mycotoxins is produced by the Fusarium species and when culturing the Fusarium moniliforme cultures on corn, a mycotoxin called Fumonisins was found to be produced (28). When analyzing fumonisins using liquid chromatography, three types of fumonisins were found namely B1 (FB1), B2 (FB2), and B3 (FB3) and all three types are isolated when allowing the fusarium to grow on corn and the concentrations of fumonisins will range from $800-12800 \mathrm{ng}$ total fumonisins/g (29).

In addition to the aflatoxins, another group of mycotoxins were found to have a similar action on humans and animals, grouped as the Ochratoxins (30-32). The Ochratoxins are mycotoxins produced by some Aspergillus species such as A. Ochraceus and A. Niger, whereas some Penicillium species such as $P$. Verrucosum and P. Carbonarius are also found to produce Ochratoxins (32). Among all the types mentioned, Ochratoxin $\mathrm{A}$ is the most common and it has the highest degree of toxicity (33-35). The Ochratoxins can be found in cereals, coffee, dried fruit, and red wine. It can be accumulated in the meat of animals and thus, meat and meat products can be contaminated with this toxin (36-39).

As previous literature indicates, fungal strains can be found in many terrestrial habitats which make the availability of different mycotoxins a very common phenomenon. Since many different fungal strains such as Penicillium, Aspergillus and Fusarium species grow very well on commodities such as crops, grains and stored animal feed, the chances of mycotoxins entering the humans or animal biological system are very high, mostly accompanied with many health concerns and medical complications (40).

\section{The chemical and physical nature of mycotoxins}

Researched confirmed that the most important mycotoxins are Citrine, Aflatoxin B1, Ergot, fumonisins akaloids, Patulin, Trichothecene, Zearalenone and Ochratoxin A and the reason behind their importance is the fact that they are involved in many human and animal diseases which sometimes leads to death (41).

Aflatoxin B1. Aflatoxins are the most important mycotoxins that are produced mainly by Aspergillus Flavus and Aspergillus Parasiticus (42), and they are mainly produced by the aspergillus species (43-45). There are four types of aflatoxins named B1, B2, G1, and G2 and can be categorized based on two characteristics: Their fluorescence color under UV light (whether it is blue or green), and their mobility during TLC (41). The chemical formula of the aflatoxin is $\mathrm{C}_{17} \mathrm{H}_{12} \mathrm{O}_{6}$ (Fig. 1) (46). The biosynthesis of aflatoxins starts with the production of norsolorinic acid which is an anthraquinone precursor joined together by the action of the enzyme II polyketide synthase followed by 15 post-polyketide synthase steps which will yield a series of toxigenic metabolites (47-52).

Citrinin. Chemically, citrine is known as $(3 \mathrm{R}, 4 \mathrm{~S})-8$ hydroxy-3,4,5-trimethyl-6-oxo-4,6-dihydro-3H-isochromene7-carboxylic acid (53) and its chemical formula is $\mathrm{C}_{13} \mathrm{H}_{14} \mathrm{O}_{5}$ (Fig. 2) (54). It is mainly produced by Penicillium Citrinum (55). Citrinin is connected to the yellow rice disease in Japan and it is a potent nephrotoxin in animals. Its acute toxicity varies with different species $(56,57)$.

Ergot alkaloids. The most important and fascinating Ergot alkaloids is the Ergotamine, produced mainly by Claviceps Sclerotia and its chemical formula is $\mathrm{C}_{13} \mathrm{H}_{14} \mathrm{O}_{5}$ (Fig. 3) (58). Ergotamine is made up of indole alkaloids that are derived from a tetracyclic ergoline ring system (59).

Fumonisins. The most important fumonisins are the fumonisin B1 and they are the product of condensation of alanine into acetate-derived precursor (60). The chemical formula of the Fumonisin $\mathrm{B} 1$ is $\mathrm{C}_{34} \mathrm{H}_{59} \mathrm{NO}_{15}$ (Fig. 4) and it is basically produced by the Fusarium species (61).

Ochratoxins. The most important ochratoxin is the Ochratoxin A, which is produced mainly by Aspergillus Ochraceus (62) and its chemical formula is $\mathrm{C}_{20} \mathrm{H}_{18} \mathrm{C}_{1} \mathrm{NO}_{6}$ (Fig. 5) (63).

Patulin. This mycotoxin is produced by the Penicillium pabulum, and its chemical name is 4 -hydroxy- $4 \mathrm{H}$-furo[3,2c] pyran-2(6H)-one (64). The chemical formula is $\mathrm{C}_{7} \mathrm{H}_{6} \mathrm{O}_{4}$ (Fig. 6) (65). This toxin was once used as an antibiotic until it was proven toxic in the 1960s and classified as a mycotoxin (64).

Trichothecenes. This group of mycotoxin contains three major toxins called T-2 toxin (Fig. 7), Deoxynivalenol (Fig. 8) and Satratoxin H (Fig. 9) and they are produced mainly by Myrothecium, Phomopsis, Trichothecium, Fusarium, Trichoderma and Stachybotrys (66-68). Chemically, trichot- 


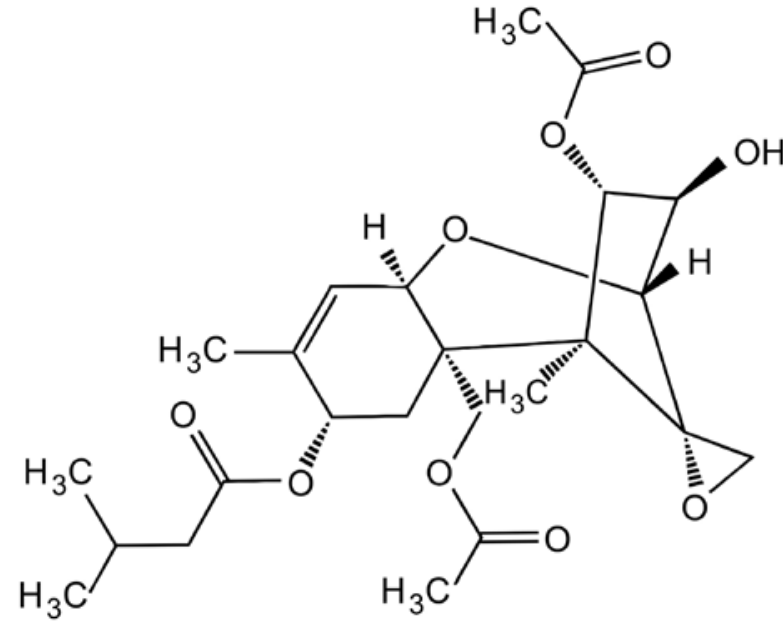

Figure 7. Chemical structure of T-2 toxin.

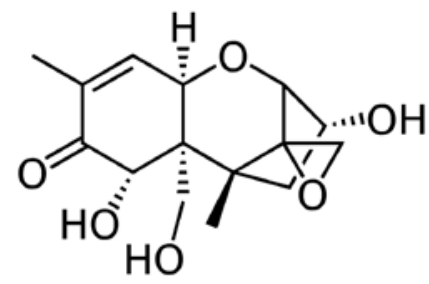

Figure 8. Chemical structure of Deoxynivalenol.

hecenes are made up of 12,13-epoxytrichothene skeletons linked up with an olefinic bond with various side chain substitutions. Trichothecenes can be classified into group A, which has hydrogen or ester type side chain at the C-8 position and include T-2 toxin, and group B which has a ketone and include fusarenon-x, nivalenol, and deoxynivalenol (69). Satratoxin is another important Trichothecene which is a macrocyclic trichothecene produced mainly by Stachybotrys Atra. Research has proven its toxicity towards humans and animals (70).

Zearalenone. This mycotoxin is mainly produced by Fusarium Graminearum and its chemical name is 6-[10-hydroxy6-oxo-trans-1-undecenyl]-B-resorcyclic acid lactone (71). The chemical formula of Zearalenone is $\mathrm{C}_{18} \mathrm{H}_{22} \mathrm{O}_{5}$ (Fig. 10) (72).

Mycotoxin chemical composition makes them strong and stable to a point where they cannot be completely destroyed during the different food processing procedures. They can contaminate the final food product which will eventually enter the humans biological system (73). When the food that is processed is mainly cereals, the contaminating mycotoxins most likely to be found are Aflatoxins, Ochratoxin A, Fumonisins, Deoxynivalenol and Zearalenone (74). Mycotoxins can be affected by different food processes such as trimming, cooking, baking, cleaning, canning, alkaline cooking, frying, roasting, flaking, nixtamalization, sorting, milling, extrusion and brewing (75). With the increase in the temperature, the effect on the mycotoxin will increase but due to its chemical nature, the concentration of the mycotoxins will be reduced. Despite this, mycotoxins cannot be completely eliminated (73). High temperature that is greater than $150^{\circ} \mathrm{C}$

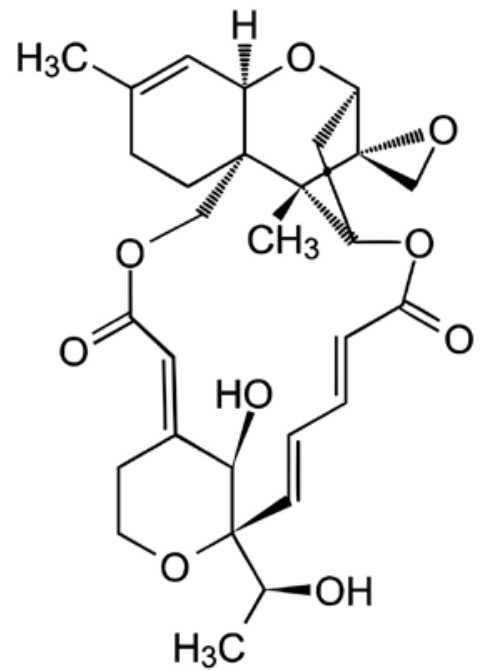

Figure 9. Chemical structure of Satratoxin $\mathrm{H}$.

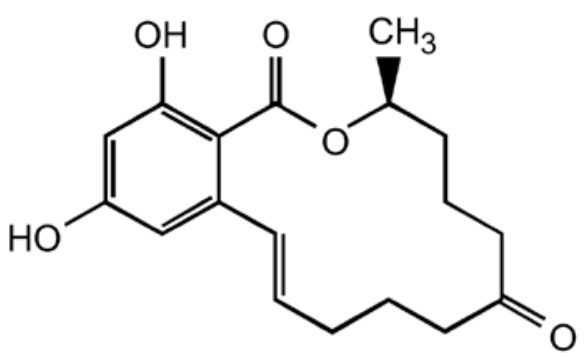

Figure 10. Chemical structure of Zearalenone.

during the extrusion was needed to reduce zearalenone greatly and aflatoxins moderately (76). In the same temperature during the extrusion process, there will be a low reduction of deoxynivalenol and a high reduction of fumonisins. Temperatures $160^{\circ} \mathrm{C}$ and higher with the addition of glucose was found to reduce fumonisin to even greater levels (73).

In another experiment, the degradation of aflatoxin was examined in different conditions and it was found that Aflatoxin can be partially or completely degraded by several sterilization techniques such as heat and irradiation. Besides that, aflatoxins can be eliminated by the addition of bisulfate, strong acids, strong bases or oxidizing agent or treatment with strong acids or bases, oxidizing agents or bisulfite. Hydrogen peroxide plus riboflavin denature aflatoxin in milk (77). Chemical stability of Nivalenol, Deoxynivalenol and Zearalenone related to moisture, $\mathrm{pH}$ and heat was studied by Lauren and Smith (78) and the results showed that Nivalenol and deoxynivalenol are stable in buffer solutions that have the range of PH 1-10, but with a PH higher than 12, high salt concentration and a temperature of $80^{\circ} \mathrm{C}$ for a long period of time, both Nivalenol and deoxynivalenol tend to break down. In the same experiment, both Nivalenol and deoxynivalenol are reduced to $60-100 \%$ by treating the contaminated food with 10,20 or $50 \%$ of the food dry weight with bicarbonate solution and raise the temperature up to 80 or $110^{\circ} \mathrm{C}$ for 2-12 days. Finally, in the case of zearalenone, the result shows that it is highly stable and cannot be broken down even when 
treated with sodium bicarbonate solution at a temperature of $110^{\circ} \mathrm{C}$ for more than 12 days (78).

All mycotoxins have at least one benzene ring which gives them thermodynamic and chemical stability, and that is mainly why they require a high temperature to desaturate and to be utilized as less complex compounds $(27,54,60,62,65,66,72,79,80)$. This stability makes mycotoxins highly resistant when it comes to decontamination and sterilization and that in turn will increase the chances of contaminating human food and animal feed $(55,72,73,81)$. Finally, the chemical and physical nature of mycotoxins makes them a very strong carcinogenic agent that can be related to different cancer types in all countries around the world.

\section{The action of mycotoxins on the cellular genome and its effect on humans}

The most dangerous mycotoxins are the aflatoxin B1 (Fig. 1) and Ochratoxin A (Fig. 5) for their lethal effect on humans and animal. Aflatoxin B1 has the highest carcinogenicity among all mycotoxins and it is capable of penetrating the cell membrane and attach to its DNA where it makes changes to the genome in order to become more stable $(2,82,83)$. Aflatoxin B1 is considered a liposoluble compound which can be absorbed from the site of exposure and move into the blood stream throughout the body (84). As soon as the aflatoxins enter the cells, they get metabolized by cytochrome P450, to aflatoxin-8, 9-epoxide which is highly reactive and unstable and requires the binding to a DNA or to the protein molecule in order to become more stable $(85,86)$. Once the highly unstable aflatoxin-8, 9-epoxide binds to the DNA molecule with high affinity, it forms aflatoxin-N7-guanine that causes GC to TA transversion mutations. This will directly affect the cell cycle by affecting the P53 gene which encodes tumor suppressor protein that inhibits the development of tumors and cancers $(87,88)$.

Ochratoxin (Fig. 5) is another mycotoxin which is given a similar importance as Aflatoxin B1 because of how it targets the kidney (89). Ochratoxin A is considered a nephrotoxin to animals and humans and is a very strong liver toxin, potent teratogen, carcinogenic and immune suppressant $(90,91)$. Ochratoxin A will mainly disturb cellular physiology in several ways, but the primary effects of it are usually associated with the enzymes that are involved in phenylalanine metabolism which inhibits the enzyme involved in the synthesis of the phenylalanine-tRNA complex $(92,93)$. Moreover, Ochratoxin A is capable of inhibiting mitochondrial ATP production and is considered a strong stimulant for lipid peroxidation $(35,94)$.

Trichothecene mycotoxins are proven to have multiple inhibition effects on eukaryote cells where they inhibit protein, DNA and RNA synthesis, mitochondrial function and effects both cell division and cell membrane of the eukaryotic cells (95). Trichothecenes are capable of inducing a programmed cell death response within infected cells, causing a reduction in downstream gene products, starting a ribotoxic stress response and activating a mitogen-activated protein kinase (96). Deoxynivalenol mycotoxin (Fig. 8) usually mediates an inflammatory response by controlling the binding activities of some transcription factors which will results in inducing cytokine gene expression (97). In animal cells, Trichothecenes are capable of inhibiting protein synthesis, inhibiting RNA and DNA synthesis; altering cellular membrane structure, interfere with mitochondria functions, initiating apoptosis, activation of MAPK and finally, activation of the cytokine (98-104).

Citrinin (Fig. 2) is considered as one of the strongest nephrotoxins to animals, and the levels of toxicity differ between species (56). Citrinin can act together with Ochratoxin A, interfere with RNA synthesis and suppress it in rodent kidneys (105). Citrinin is known to inhibit cytokine expression and reduce the interleukin- 4 in T-helper type 1 which would result in increasing the risk of allergies in humans (106). It is considered genotoxic at high concentrations to cultured human lymphocytes (107). Finally, Citrinin is considered a nephrotoxin which causes nephropathy and impose oxidative stress, or increase the permeability of mitochondrial membranes (108). Ergot Alkaloids mycotoxins are a type of Citrinin, and they are known to induce humans ergotism, low nerve fever in humans and have a strong influence on fertility (109-111). Although certain cleaning processes for grains has overcome the problem of ergotism, it is still considered a significant animal problem which causes symptoms such as abortion, suppression of lactation, hypersensitivity, ataxia and gangrene $(112,113)$ and smooth muscle contractions (114). Despite its toxicity, Ergot Alkaloids mycotoxins and its derivatives are used widely in abortifacient and as a drug to accelerate uterine contractions during labor (114). They are also used for the treatment of migraine headaches, prolactin inhibitors for the treatment of Parkinsonism and for the treatment of cerebrovascular insufficiency (59). Unfortunately, the use of ergot alkaloids may result in the development of human ergotism (115).

Fumonisin B1 (Fig. 4) is an important Fumonisins mycotoxin which was reported to be a hepatotoxic and carcinogenic toxin $(28,116,117)$. In addition, fumonisin B1 was reported to cause apoptosis in the liver of rats (118) and there is a possibility that it can be linked to esophageal cancer (119). FB1's main action is to disrupt sphingolipid metabolism which induces lipid peroxidation that will end up altering the cell membrane, causing cell death through apoptosis. It also has the potential of inhibiting protein synthesis and in higher concentration to inhibit DNA synthesis (120). It was proven to have some carcinogenic activity by stimulating ${ }^{3} \mathrm{H}$ thymidine incorporation (121). Fumonisin mycotoxins are involved in the neural tube defects in animals, and it was hypothesized that it can have the same effect on humans. A cluster of anencephaly and spina bifida cases in Texas in the USA is related to fumonisins mycotoxins infection in corn products $(122,123)$ and it was evaluated by the International Agency for Research that fumonisins have a cancer risk to humans. Its carcinogenicity is classified as group 2B which means probably carcinogenic (124). Another mycotoxin that affects humans on a cellular level is Patulin (Fig. 6) which is just as toxic at high concentration in but there is not enough evidence for natural poisoning, and its recorded poisonous effects are inconclusive (125).

Trichothecene mycotoxins were proven to be extremely potent inhibitors of eukaryotic protein synthesis, and were found to interfere with initiation, elongation, and termination stages of protein synthesis. They are the first mycotoxin from the trichothecene group known to inhibit peptidyl transferase 
activity during protein synthesis $(126,127)$. The way trichothecenes inhibit peptidyl transferase is by binding to the same ribosome-binding site, leading to correlation with different functional groups and subsequently affecting the protein synthesis process (128). Among all Trichothecene mycotoxins, Deoxynivalenol is the most commonly found mycotoxin in different grains and once they are ingested, are reported to cause nausea, vomiting, and diarrhea with refusal for food and weight loss in animals (129). Deoxynivalenol was found to have a mitogen-activated protein kinase-mediated IL-8 expression in cloned human monocytes and peripheral blood mononuclear cells where the concentration of deoxynivalenol is from 250 to $1000 \mathrm{ng} / \mathrm{ml}$. This will induce both IL-8 mRNA and IL- 8 heteronuclear RNA which is an indicator of IL-8 transcription in human U937 monocytic cell line in a concentration-dependent manner (130).

Other Trichothecene mycotoxins that were found to have a great toxic effect on humans and animals are T-2 (Fig. 7) and diacetoxyscirpenol. Both were proven to be immunosuppressive in which they reduce resistance towards different infections and microbes $(129,131)$. T-2 mycotoxin was proven to induce apoptosis at $10 \mathrm{ng} / \mathrm{ml}$ concentration (132) and was reported to inhibit the platelet aggregation and the release of dense bodies with a change in the membrane permeability (133). On the other hand, diacetoxyscirpenol is capable of inhibiting protein synthesis, has high immunomodulatory effects (134) and was reported to cause alimentary intoxication, food poisoning and induce hematological symptoms (135). Moreover, it was proven that T-2 and diacetoxyscirpenol are capable of causing several dermatological, gastrointestinal, and neurologic symptoms in humans and animals (136). Finally, T-2 and diacetoxyscirpenol are hypothesized to be associated with a humans disease called alimentary toxic aleukia in which the infected person will have skin inflammation, continuous vomiting, and damage to hematopoietic tissues that gives rise to blood cells and in advanced stages, cause central nervous system disorders, oral cavity, and severe bleeding from the nose, mouth, and vagina (111).

Zearalenone mycotoxins (F-2) (Fig. 10) are a unique mycotoxin that is biologically potent but is hardly toxic and resembles $17 \beta$-estradiol, which is an ovary hormone which humans produce to help the ovaries bind to estrogen receptors in the target cells. Therefore, it can be classified as a nonsteroidal estrogen or mycoestroge (137) and used to reduce the postmenopausal symptoms in women (138). The major effects of Zearalenone are on the reproduction in females, where it affects reproductive organs and their function, eventually leading to a medical condition called hyperestrogenism (137). Zearalenone in its reduced form, zearalenol, is known to increase estrogenic activity (139) but it was proven to cause disrupted conception, abortion, and other problems in female pigs (140) and that can be hypothesized for humans as well.

\section{Mycotoxins and their carcinogenicity}

The effects of mycotoxins on humans and animals will vary based on the nature of the toxins. While several are considered to be mutagenic; it was proven that Aflatoxin B1, Ochratoxin A and Sterigmatocystin are strong carcinogens (17). In a study made to identify the DNA-attacking ability of carcinogenic mycotoxins, six Penicillium toxins that include patulin, Citrinin, penicillic acid negativeluteoskyrin, positive-rugulosin, and PR-toxin, 5 aspergillus toxins including $\mathrm{O}$-acetylsterigmatocystin, sterigmatocystin, O-acetyldihydrosterigmatocystin aflatoxin B1 and aflatoxin G1, and two fusarium toxins that include zearalenol-b and zearalenone, all these mycotoxins were found to have destructive ability towards genomic DNA (141). Although these 13 mycotoxins have the ability to attack the genomic DNA, 8 of them were found to be highly carcinogenic, including penicillic acid, citrinin, patulin, negative-luteoskyrin, positive-rugulosin, sterigmatocystin, aflatoxins B1, and G1 (141).

In another experiment conducted on mice, the effect of luteoskyrin and cyclochlorotine mycotoxins was investigated, and it was found that both toxins have hepatotoxic and hepatocarcinogenic activities on rats (142) with a hypothetical possibility to affect humans in a similar fashion. Fumonisin mycotoxins were found to be carcinogenic in rats due to their action in inhibiting ceramide synthase in vitro which in turn would enhance the production of tumor necrosis factor $\alpha$ (TNF $\alpha$ ). This leads to the initiation of cells apoptosis (143). In addition, an experiment was conducted using 28 mycotoxins to investigate their action against hepatocytes of rats and mice. The results of the experiment showed that unknown carcinogenic mycotoxins such as 5,6-dimethoxysterigmatocystin, versicolorins $\mathrm{A}$ and $\mathrm{B}$, averufin, xanthomegnin, luteosporin, and chrysazin, known carcinogenic mycotoxins such as aflatoxin B1 (Fig. 1), sterigmatocystin, luteoskyrin, Ochratoxin A (Fig. 5), azaserine, mitomycin $\mathrm{C}$, and actinomycin $\mathrm{D}$ have the tendency to elicit DNA repair synthesis, which suggest the possibility of these mycotoxins to be genotoxic carcinogens (144). On the other hand, some carcinogenic mycotoxins such as penicillic acid, patulin, griseofulvin, and rugulosin were not found to elicit DNA repair synthesis and suggest the possibility of these mycotoxins being nongenotoxic carcinogens (144).

Aflatoxin B1. Aflatoxin B1 has a ubiquitous nature and is considered a toxic metabolite, making it a serious public health concern. Furthermore, aflatoxin B1 (Fig. 1) toxin contamination is related to liver diseases (145). Aflatoxin B1 is said to have an active role in causing hepatic and extrahepatic carcinogenesis in both humans and animals by inducing a DNA single strand break (146) and through bio activation of Aflatoxin B1 to its epoxide metabolite. As a result, it will interact with the DNA molecule which will finally lead to neoplastic transformation of the cells (147). The activation of Aflatoxin B1 is accomplished by two approaches, chemical and enzymatic in which the Aflatoxin B1 will be biologically active. The chemical activation of the Aflatoxin B1 will be through the chemical oxidation of dimethyldioxirane whereas the enzymatic activation will be through the cytochrome P450. Combined, they are a mixedfunction oxidase that will give rise to a mixture of exo and endo-8, 9-epoxides (148). The exo-8, 9-epoxides will interact with the DNA molecule by attacking the nitrogen atom at the 7 position (N7) of guanine at the C8 of the epoxide by the Sn2 reaction. This process initiates the trans adduct that will lead to the development of a malignant cell. They are considered to be carcinogenic agents $(149,150)$. On the other hand, it is not capable of interacting with DNA molecules. Hence, it is not considered a carcinogenic agent (148). 
It was reported that almost half of the hepatocellular carcinomas (HCC) were reported in the part of the world that witnessed high levels of Aflatoxin B1 contamination in food where a mutation in the 249th codon of the P53 tumor suppressing gene (151). The mutation caused in this codon is in the form of transversion in the third position of this codon and will cause the insertion of serine at the 249 in the mutant protein (152). In addition to the $\mathrm{G}-->\mathrm{T}$ transversion, Aflatoxin B1 will cause G-->T and C-->A transversions into adjacent codons but with reduced frequency but it was proven only as G-->T transversion at 249 codon. It turns out that the mutant serine 249 p53 protein are responsible for the mutation at p53 in HCC from aflatoxin B1 in the areas that were reported to have aflatoxin $\mathrm{B} 1$ contamination in the food (153). This confirmed that aflatoxin B1 is hepatocarcinogenic (154). In another study, there was an increase of the hepatocellular carcinoma in Mozambique and Transkei, and several parts of Asia (155) including China (156) and Africa including Kenya (153).

Inhalation of aflatoxin B1 is thought to cause primary lung cancer due to the activation of it to its biologically active form 8, 9-epoxide where the rate of 8,9-epoxide was measured using AFB1-glutathione (AFB1-GSH) conjugate by HPLC with aflatoxin b1 at a concentration of $124 \mu \mathrm{m}$. Rates of activation were less than in the liver cells most probably due to the CYP-containing cells that are less abundant in the lungs than in the liver (157). In another study, the X-ray crosscomplementing group 1 protein (XRCC1) which is involved in the repair mechanism of the single strand DNA was investigated in the presence of aflatoxin. A substitution of guanine to adenine was found at codon 399 and that in turn was found to increase the risks of adenocarcinoma of the lung (158). The presence of aflatoxin B1 has been confirmed in two cases of human lung cancer using thin-layer chromatography and fluorescence microscopy $(159,160)$. Finally, the expression of GSTM1-1 that is responsible for the production of cytosolic Glutathione S-transferases helps in detoxifying several carcinogenic electrophiles in the presence of polycyclic aromatic hydrocarbons that serves as the main compound, yielding substrates for these enzymes, and naturally was affected by the presence of Aflatoxin B1, which leads to inactivation of GSTM1-1 and increased risk factor for lung cancer (161).

Ochratoxin A. Ochratoxin A (Fig. 5) was reported to be associated with different effects on humans and animals but their nephrocarcinogenicity was found to be the most important effect, and that made it a major public health concern. In an experiment conducted on male Fischer rats that were fed Ochratoxin B1, a renal tumor was discovered within the first six months, and the tumor incidents increased by $25 \%$. This is because the genes responsible for kidney injury and cell regeneration were significantly influenced by the action of Ochratoxin A (162). Ochratoxin A was found to cause an alteration of gene expression that resulted in affecting calcium homeostasis which disrupts the different pathways regulated by the HNF4 $\alpha$ and Nrf2 in the kidney (163). In addition, Ochratoxin A was found to have a small influence on the expression of genes involved in DNA synthesis and repair and ones induced as a result of DNA damage. There was minimal to no influence at all on the genes that are responsible for apoptosis $(163,164)$. Ochratoxin was also found to effect Nrf2- regulated genes in the kidney that is required for the chemical detoxication and antioxidant defense within the cell. That in turn affects the cell's defense mechanism while also causing an increase in the kidney oxidative stress, which contributes to the Ochratoxin A carcinogenic nature (165). Ochratoxin A is suggested to have a renal carcinogenesis effect on the kidneys and its mode of action is by the means of direct genotoxicity through covalent DNA adduct formation. This information should be taken into consideration for Ochratoxin A for OTA human risk assessment (166).

The alteration caused by Ochratoxin A could lead to single cell death in kidney and stimulates cell proliferation and an enlarged cellular nucleus which indicates blocked nuclear division during mitosis. Exposure to Ochratoxin A could also lead to overexpression of mitosis regulators such as mitotic protein kinases Polo-like kinase 1, Aurora B and cyclin-dependent kinase 1, cyclins and cyclin-dependent kinase inhibitors, topoisomerase II and surviving (167). Ochratoxin A (Fig. 5) is classified as a ubiquitous nephrotoxic mycotoxin and it was reported to be responsible for human Balkan endemic nephropathy and involved in urinary tract tumors. For this reason, it was classified by the Agency for Research on Cancer as a possible carcinogen belonging to group 2B (168). Ochratoxin A has a genotoxic activity on the cell DNA followed by oxidative metabolism, which plays a major role in Ochratoxin mediated carcinogenesis. It can be divided into direct modes of action where Ochratoxin A is involved in covalent DNA adduction and indirect modes where Ochratoxin A is involved in oxidative DNA damage (169). Ochratoxin OTA is a genotoxic carcinogen because of their ability to oxidase DNA lesions and the direct DNA adducts through quinone formation (170). Ochratoxin A was proven to increase phosphorylation of atypical-PKC which in turn leads to a downstream activation of ERK1 and ERK 2 and their substrate ELK1, ELK2 and p90RSK where PKC and the MEK-ERK MAP-kinase pathways are activated by Ochratoxin A involved in cell proliferation, cell survival, anti-apoptotic activity and most importantly renal cancer development (171).

A study on rodents supported the involvement of Ochratoxin A mycotoxin in developing breast cancer through genetic damage, and the study hypothesized the possibility of the Ochratoxin A in causing breast cancer. The validity of that hypothesis relates to data that show an increase in breast cancer cases when a number of people in a population migrate from one geographic area to another (172). Ochratoxin A was hypothesized to be involved in testicular cancer which is one the most common cancer affecting young men due to adducts in testicular DNA where the consumption of Ochratoxin during pregnancy and during young childhood would cause lesions in the testicular DNA during puberty. These lesions will develop into testicular cancer (173-175).

Citrinin. Citrinin (Fig. 2) is considered as nephrotoxic mycotoxin (176), and traces of Citrinin were found in contaminated food in areas known to have endemic nephropathy, diseases that are associated with urinary tract cancer. It produced micronuclei and DNA migration and had the potential of inducing micronuclei in HepG2 (human-derived liver cell line), and can cause DNA damage, effectively increasing the risk of cancer in humans (177). Citrinin was proved to 
induce chromosomal aberrations in both humans and rat liver microsomes. In addition, Citrinin can also cause complex translocations with the cellular DNA in a high frequency, and is capable of inducing defects in chromosomal coiling (178), which may lead to the formation of DNA adducts (179). In an experiment performed to assess the effect of Citrinin on viability and DNA fragmentation and chromosome aberrations in mouse bone marrow cells and cultured Vero cells, Citrinin was found to be a weak cytotoxic. However, it causes DNA fragmentation and chromosome aberrations that may lead to cancer, apoptosis, and carcinogenesis (180). Citrinin was found to inhibit cell-free microtubule polymerization and it has an aneuploidogenic activity. Citrinin is also a source of mitotic arrest and CREST-positive micronuclei where it will induce the formation of micronuclei containing whole chromosomes or chromatids (181). Finally, some strong evidence suggests that Citrinin is involved in the development of Balkan endemic nephropathy and associated urinary tract tumors (182).

Fumonisins. Fumonisin (Fig. 4) is a potential cancer causing agent in humans (183). An experiment was conducted on 25 rats where their food was mixed with Fumonisin B1 for a period ranged from 6 to 26 months and the result of the experiment confirmed that Fumonisin B1 is hepatocarcinogenic and hepatotoxic $(184,185)$. Fumonisins are capable of inhibiting the biosynthesis of sphingosine and the complex sphingolipids by inhibiting the enzyme ceramide synthase and that, in turn, will lead to the increase of free sphinganine and the free sphingoid bases which are toxic to cells. In cultured cells that are treated with Fumonisin B1, the accumulation of bioactive long-chain sphingoid bases and depletion of complex sphingolipids essential for cell growth and development lead to inhibiting the growth, increasing cell death, and influence on mitogenicity that would lead to the development of cancer in fibroblast cell line $3 \mathrm{~T} 3$ (186).

Fumonisins were found correlated with incidence of esophageal cancer in both Southern and Northern Africa and China, neurodegenerative disease $(187,188)$ and leukoencephalomalacia in horses (28). It was proven that fumonisin B1 are involved in the development of renal carcinomas in male rats, and liver cancer in female mice which could occur in humans as well (189). Finally, Fumonisin B1 was found to cause inhibition in the production of ceramide synthase in vitro which in turn enhances tumor necrosis factor $\alpha$, production and cause apoptosis (143). Finally, Fumonisins mycotoxins were found to contribute to the development of neural tube defects among Mexican-American woman in south Texas, and was characterized by defects in the brain, spine, or spinal cord of fetus in the first month of pregnancy (190).

Patulin. Patulin (Fig. 6) and its precursor 6-methylsalicylic acid are derived from Acetyl-CoA which makes them polyketides and carcinogenic mycotoxins $(191,192)$. They are capable of causing gene mutations in different mammalian cells (193). The administration of patulin subcutaneously twice a week for 15 months showed the development of malignant tumor cells in the area of administration which proved the carcinogenic effect of this mycotoxin. It can by hypothesized in humans as well $(64,194-196)$ although the carcinogenic effect of patulin was not confirmed by Osswald at al (197), patulin was confirmed to be toxic to the mice born to patulin treated mothers and deaths occurred in both males and females.
Patulin is found to be mutagenic, carcinogenic and teratogenic and it has the tendency to induce intestinal injuries (198) and it has the ability to attack cellular DNA in bacteria (199) and humans (141), that can lead to the development of tumors, and cancer.

It was proposed that the toxicity of patulin for intestinal cells involves an inactivation of the active site of protein tyrosine phosphatase (PTP). The protein tyrosine phosphatase is a key regulator of intestinal epithelial barrier function, and the active site of PTP contains a cysteine residue (Cys215) which is important and required for phosphatase activity. On the other hand, the sulfhydryl-reacting compounds such as acetaldehyde decrease the transepithelial resistance (TER) through a covalent modification of cysteine residue Cys 215 of the protein tyrosine phosphatase and this toxicity can lead to damage in the intestinal cells that eventually may lead to intestinal and stomach cancer (198) and this evidence can be used to hypothesize and indicate the involvement of patulin in the development of intestinal and stomach cancer in humans. Patulin was found to inhibited the cell-free microtubule polymerization, it has the ability to bind covalently to reactive thiol groups of microtubule proteins, and deactivates the protein. It induces the formation of micronuclei that contains the whole chromosomes or chromatids, it also induces the formation of micronuclei containing acentric chromosomal fragments, and that indicates its clastogenic ability, and finally, Patulin has both aneuploidogenic and clastogenic properties that could contribute to the carcinogenicity of this mycotoxin in the long-term studies which in turn could be hypothesized in humans as well (181).

Trichothecenes. T-2 (Fig. 7) are mycotoxins that belong to Trichothecene mycotoxin and is considered as immunosuppressive, cytotoxic and lymphocytic and carcinogenic mycotoxin in mammalian cells (17) although the work of Ueno et al (200) on Salmonella typhimurium suggested that trichothecenes have failed to demonstrate mutagenicity. T-2 is capable of inducing breaks in the DNA of lymphocytes when administrated in vivo and in vitro and once fibroblast cells are treated with this mycotoxin incorporation with ${ }^{3} \mathrm{H}$ thymidine, unscheduled DNA synthesis will take place (201). The susceptibility of newborn and immature animals to T-2 are more compared to adults and it causes a high degree of edema and dermal toxicities through the direct attack of trichothecenes on the capillary vessels (202). In the presence of aflatoxin B1 (Fig. 1), the trichothecenes nivalenol, will enhance the aflatoxin B1-induced hepatocarcinogenesis and T-2 lack any hepatocarcinogenesis ability and that was confirmed by an investigation in the presence of GST-P-positive foci that acts as a marker for the presence of hepatocarcinogenesis (203). Although it was proposed (204) that under the experimental conditions in both in vivo and in vitro, no damage took place in the hepatic DNA, T-2 has the ability to decrease responses to mitogens in human lymphocytes in vitro (205).

The exposure to trichothecene mycotoxin can activate apoptosis in both in vitro and in vivo within many organs that include the lymphoid organs, the hematopoietic tissues, with in the liver and the intestine, in the bone marrow and finally the thymus $(95,206,207)$ and it inhibits the protein synthesis $(206,208)$ and it was found to induce cellular necrosis and karyorrhexis in the dividing tissues of the intes- 
tinal mucosa, bone marrow, spleen, testis, and finally, the ovary (208).

Another trichothecene mycotoxin that has the ability to increase the frequency of inducing mutation and cancer is Nivalenol. Nivalenol can also be involved in casing sister chromatid exchange in Chinese hamster cells and it can case DNA damage making it a potential genotoxic agent (205) which can be hypothesized in humans as well. Nivalenol acute toxicity can lead to bone marrow toxicity and Nivalenol chronic toxicity would lead to leucopenia (209). Unfortunately, there is no clear evidence of Nivalenol carcinogenicity in experimental animals or humans and an investigation was carried on cell lines in vitro $(205,210)$.

Diacetoxyscirpenol mycotoxin is another group of trichothecene mycotoxin which is known to inhibit the proliferation and Ig production in the mitogen-stimulated human lymphocytes (211) and it causes esophageal hyperplasia but is not capable of inducing cancer in rats (212) and despite its toxicity, it was used as a chemotherapeutic agent for cancer treatment (132).

Finally, FUS-X in another group of trichothecene mycotoxin which is capable of causing an immunosuppressive response, carcinogenicity, cytotoxicity in experimental animals and possibly in humans as well (208). FUS-X is toxic to many cell types such as murine thymocytes, lymphocytes, and gastric epithelial cells but they have a high degree of toxicity to human hepatoblastoma cells (213). It can initiate apoptosis in mouse thymocytes in vivo as well as in vitro $(214,215)$ that can be hypothesized in humans as well. Although FUS-X was confirmed to be carcinogenic in animals (208), no clear evidence is available on its carcinogenicity in humans (213). FUS-X is highly cytotoxic to several type of cells $(216,217)$. It is suggested that it has teratogenicity or chromosomal effects, but no strong evidence is available to support this hypothesis (213) although (214) has demonstrated that FUS-X has genotoxic potentials when administered or exposed at low levels. Bony et al (210) concluded that due to the lack of strong evidence on FUS-X carcinogenicity in both animal and man, FUS-X is not considered as a carcinogenic agent.

Zearalenone. Zearalenone (Fig. 10) shows hormonal activity in many animal species which makes it genotoxic, carcinogenic or both at the same time (218), and it can impose changes in the reproductive organs and systems of many laboratory animals such as mice, rats and different domestic animals such as horses (205). Due to this ability, it is hypothesized that Zearalenone can be involved in causing reproductive organ cancer in both humans and animal. Zearalenone was found to be carcinogenic in mice and capable of causing hepatocellular adenomas and pituitary tumors (205). More work is needed in order to confirm its carcinogenicity in humans. Despite its toxicity and carcinogenicity, Zearalenone is used to increase the meat production in cattle in some countries, and it is forbidden in other countries like some European countries (218). That is most probably due to the lack of evidence or data that supports its toxicity and carcinogenicity in humans and animal (219).

A high incident of esophageal cancer was reported in areas known to have mycotoxin contamination that includes zearalenone and the ability of this mycotoxin in inducing hyperkeratotic papillomatous in the forestomach of a rat esophageal squamous epithelium (220) suggested the involvement of this mycotoxin in causing and developing a tumor in the digestive tract (221-224). When cultured Vero cells and mouse bone marrow were treated with zearalenone, the mycotoxin induces the formation of micronuclei, the development of clastogenicity and induces genotoxicity (225). Zearalenone has a DNA-attacking ability (141).

In an experiment to demonstrate the effect of estrogen present in the feed of animals, Zearalenone was found to induce mammary tumor in $\mathrm{C} 3 \mathrm{HA}^{\mathrm{vy}} \mathrm{fB}$ mice and further studies need to be conducted in order to confirm wether Zearalenone has cancer inducing ability or carcinogenic effects on target organs like diethylstilbestrol and the steroidal estrogens (226). A study was conducted on NTP mouse where the mice were given a dose of Zearalenone through food, and the result of this study showed the ability of Zearalenone in inducing hepatocellular adenomas in the female mice. Zearalenone was also found to cause DNA damage in Bacillus subtilis and it showed DNA adducts in female mice kidney and liver (227,228). Finally, it was shown that the results of this study confirmed the genotoxicity and the ability of zearalenone to induce hepatocellular adenomas in mice but not in rats (227). Since there is evidence to prove that these result can relate to humans, these results can be used to hypothesize the involvement of Zearalenone in developing liver, kidney and other types of cancer in humans.

\section{Mycotoxin research gaps and the recommended new research areas}

Many studies were conducted on the effect of mycotoxins on the biological system and their carcinogenicity-toxicity as mentioned before in this study but unfortunately, many of these studies were done on animal models and the action of mycotoxins in human biological systems were simply hypothesized and no solid data were generated for many mycotoxins. As mentioned earlier, food products that can be contaminated with mycotoxins include cereal (maize, sorghum, pearl millet, rice, and wheat), oil seeds (ground nut, soybean, sunflower, cotton), spices (chilies, black pepper, coriander, turmeric, and ginger), tree nuts (almonds, pistachio, walnuts, and coconut) and finally milk (27,229-232). In addition, aflatoxins are found in the contaminated tobacco leaves (233). Finally, aflatoxins can be present in dry soil, which can move to the underground water with rain and be ingested by humans and animals through the drinking water (234). All these food sources and food products are the basic food items for people around the world which make their contamination with mycotoxin considered as a major health concern for their high carcinogenic-toxic nature and potential in both animals and humans biological system (40).

It is well known that the availability of safe and edible food is essential for sustaining humans and animal life and the fact that food shortage was the reason behind provoking many wars, people started to store and preserve food on large scale for longer time to avoid any shortage that aid in storing and transporting food items in different forms of packages and containers. That happened right before the Second World War and continues to grow exponentially after that (235). As the food industry became bigger after the Second World War (236), packaging and distribution importance grew 
exponentially, and both processes became more susceptible to different weather conditions and the exposure to different microorganisms that may lead to food spoilage and contamination with different microorganisms including fungi and the mycotoxins they produce $(237,238)$. An increase in the rates of testicular cancer incidences across Europe was observed post Second World War (239) and the reasons for it was not clear. It can hypothesized that the reasons for it can be linked to the increase in the stored food contamination with mycotoxins that can lead to testicular cancer $(173,174)$.

During and after the 2nd World War, there was an increase in the incidents of lung cancer in Coastal Georgia specifically between males working in the shipyards in a warm and humid conditions (240). Due to the high humidity, tobacco leaves were contaminated with Aspergillus Flavus that produces aflatoxin B1 (23) which is a highly carcinogenic substance that was associated with different cancer types including lung cancer (161). No solid data were generated to support the induction of human lung cancer by aflatoxin B1 but it can be hypothesized that their involvement induce lung cancer since aflatoxin B1 inactivates GSTM1-1 that is responsible for the production of cytosolic Glutathione S-transferases that helps in detoxifying several carcinogenic electrophiles that cause lung cancer, hence additional lab experiments need to be conducted to confirm this involvement. Moreover, aflatoxin B1 was suggested to cause primary lung cancer also through the activation of GSTM1-1 (161) and this mycotoxin can be inhaled and cause a direct effect on the lung cells (157) and that can indicate the effect of mycotoxin in causing lung cancer, but very limited data were collected in this area and further studies need to be conducted.

Another study was conducted in Norway where it was found that the rates of breast cancer increased greatly during and after World War II and the reasons were not conclusive, and they linked the increase in the breast cancer rate to the change in the people's lifestyle (241). The fact that eating habits and food storage and transportation changed greatly during and after World War II, the possibility of food contamination increased greatly and fungal contamination started to become a common phenomenon in stored food and mycotoxin contamination could spread widely. Mycotoxins such as Aflatoxin B1 (Fig. 1) and Ochratoxin A (Fig. 5) were confirmed to suppress tumor suppressor genes BRCA1, BRCA2 and P52 (2,172). A hypothesis can be made to conclude the involvement of mycotoxin in inducing breast cancer around the world, but there is a huge gap in this area and additional laboratory work need to be established to confirm it. In addition, HER-1, HER-2 and the c-myc oncogenes were found to be overexpressed in many breast cancer cases (242-244) and that can also be related to the involvement of mycotoxins since they have the ability to impose different changes in the human genome but further studies need to be conducted.

Patulin (Fig. 6) causes an inactivation of the active site of protein tyrosine phosphatase (PTP) and this protein is a key regulator of intestinal epithelial barrier function and the active site of PTP contains a cysteine residue (Cys215). This is important and required for phosphatase activity and sulfhydryl-reacting compounds such as acetaldehyde decrease the transepithelial resistance (TER) through a covalent modification of cysteine residue Cys215 of the protein tyrosine phosphatase. This toxicity can lead to damage in the intestinal cells that eventually may lead to intestinal and stomach cancer.

Some mycotoxins such as Fumonisins can cause neurodegenerative disease $(187,188)$. Their mode of action can be further studied to detect if they are involved in causing brain cancer and tumors by studying their effect on different genes in the brain. Fumonisins were also found to be involved in the development of neural tube defects among Mexican-American woman in south Texas which is characterized by defects in the brain, spine, or spinal cord of fetus in the first month of pregnancy (190) this involvement can also be used to hypothesize the involvement of Fumonisins in causing brain cancer in humans and further studies need to be conducted to support and confirm this hypothesis.

Zearalenone mycotoxin (F-2) major effects will be on the reproduction ability in females where they effects the reproductive organs, and their functions which will eventually lead to a medical condition called hyperestrogenism (137) and this phenomenon can be studied further to uncover if F-2 can be involved in developing ovary cancer. Finally, Fumonisin B1 was found to cause inhibition in the production of ceramide synthase which will lead to enhancing tumor necrosis factor $\alpha$, production leading to apoptosis (143) and the ability of this mycotoxin to induce apoptosis can be used to detect the involvement of this mycotoxin in causing skin cancer.

\section{Conclusions}

Many mycotoxins have the ability of causing major changes to the human genome which may result in the development of cancer, and many other mycotoxins are capable of causing highly toxic effects on the biological systems they enter. The different mycotoxins that can cause cancer are Aflatoxin B1, Citrinin, Fumonisins, Patulin, Trichothecene and Zearalenone. The role of mycotoxins in causing cancer will vary with the type of mycotoxin and it will depend on the mode of action within the biological system.

Aflatoxin B1 (Fig. 1) can penetrate the cell membrane and attach to its DNA where it causes irreversible mutations. As soon as aflatoxin B1 enters the cells, they are metabolized by cytochrome $\mathrm{P} 450$, to aflatoxin-8, 9-epoxide which is highly reactive and unstable and requires the binding to a DNA or to the protein molecule in order to become more stable and it will form aflatoxin-N7-guanine that cause GC to TA transversion mutations which will directly affect the cell cycle by affecting the P53 gene which encodes for tumor suppressor protein that inhibits the development of cancer.

Ochratoxin A (Fig. 5) can cause an alteration of gene expression that results in affecting calcium homeostasis which will disrupt the different pathways regulated by the HNF4 $\alpha$ and Nrf2 in the kidney, influence the expression of genes that are involved in DNA synthesis and repair, in response to DNA damage and it has a very small influence on the genes that are responsible for apoptosis. Ochratoxin A can cause genotoxicity by forming a DNA adduct and single cell death. Furthermore, Ochratoxin A can increase phosphorylation of a typical-PKC which in turn will lead to a downstream activation of ERK1 and ERK 2 and their substrate ELK1, ELK2 and p90RSK where PKC and the MEK-ERK MAP-kinase pathways acti- 
vated by Ochratoxin A are involved in cell proliferation, cell survival, anti-apoptotic activity and most importantly renal cancer development. Ochratoxin A is suggested to have a renal carcinogenesis effect. Its mode of action is by means of direct genotoxicity through covalent DNA adduct formation. The effects of aflatoxin B1 and Ochratoxin A in causing breast cancer and lung cancer are demonstrated in only a few studies and additional studies need to be conducted in order to confirm the course of action which will help in controlling and reducing the rates of these cancers which are considered as the most common cancers in the world.

Citrinin produced micronuclei and DNA migration and it has the potential of inducing micronuclei. Citrinin would cause DNA damage which would increase the risk of cancer in humans. Citrinin can induce chromosomal aberrations in both human and rat livers and it can cause complex translocations within the cellular DNA at a high frequency and it is capable of inducing defects in chromosomal coiling which may lead to the formation of DNA adducts. Apart from this, it can cause DNA fragmentation and apoptosis and finally, it can cause a mitotic arrest and CREST-positive micronuclei where it will induce the formation of micronuclei containing a whole chromosome or chromatids and will eventually lead to cancer development.

Fumonisins (Fig. 4) are capable of inhibiting the biosynthesis of sphingosine and the complex sphingolipids by inhibiting the enzyme ceramide synthase. That, in turn, will lead to the increase in free sphinganine and the free sphingoid bases which are toxic in cells, and that will inhibit the growth, increase cell death, and initiate involvement in mitogenicity that would lead to the development of cancer.

Patulin (Fig. 6) will cause an inactivation of the active site of protein tyrosine phosphatase (PTP) and this protein is a key regulator of intestinal epithelial barrier function. The active site of PTP contains a cysteine residue (Cys215) which is important and required for phosphatase activity and sulfhydryl-reacting compounds such as acetaldehyde. Acetaldehyde decreases the transepithelial resistance (TER) through a covalent modification of cysteine residue Cys 215 of the protein tyrosine phosphatase and this toxicity can lead to damage in the intestinal cells that may eventually lead to intestinal and stomach cancer.

$\mathrm{T}-2$, a trichothecene mycotoxin is capable of inducing breaks in the DNA of lymphocytes when administered in vivo and in vitro once the fibroblast cells are treated with this mycotoxin combined with ${ }^{3} \mathrm{H}$ thymidine. In addition, Nivalenol, a trichothecene mycotoxin is also involved in causing chromatid exchange in cells and it can cause DNA damage and that makes it a potential genotoxic agent. Finally, trichothecene mycotoxin can inhibit the proliferation and Ig production in the mitogen-stimulated human lymphocytes and it can induce apoptosis, the migration of sister chromatids as well as cause protein synthesis inhibition. The action of T-2 and Nivalenol on a cellular level can be responsible for the development of tumors and cancer.

Zearalenone (Fig. 10) shows hormonal activity in many animal species which makes it genotoxic, carcinogenic or both at the same time, and it can impose changes in the reproductive organs and systems of many laboratory animals such as mice and rats and different domestic animals such as horses.
Thus, Zearalenone is capable of causing reproductive organ cancer in both man and animal.

The cancers that can be caused by mycotoxins include liver cancer, kidney cancer, esophageal cancer, lung cancer, renal cancer, breast cancer, testicular cancer, stomach cancer and reproductive organ cancer. Considering the danger caused by mycotoxins, additional investigations need to be conducted to confirm the ability of each mycotoxin in inducing cancer, as stated above.

\section{Acknowledgements}

The first author would like to sincerely thank Universiti Sains Malaysia for the USM Postgraduate Fellowship. All authors acknowledge the Universiti Sains Malaysia for Research University Team Grant (RUT) grant nos: 1001/CIPPT/812196 and 304/CIPPT/6313241.

\section{References}

1. Sulaiman MR, Chye FY, Hamid AA and Yatim AM: The occurrence of aflatoxins in raw shelled peanut samples from three districts of Perak, Malaysia. Electronic Journal of Environmental and Food Chemistry 6: 2045-2052, 2007. http://eprints.ums.edu. $\mathrm{my} / 3769 /$.

2. Moradi S, Azari H, Anarkoli IJ, Qasemi-Panahi B, Elhami S and Forouharmehr A: Effect of aflatoxin B1 on BRCA1 and BRCA2 genes expression under in vitro cultured cell line of normal Human Mammary Epithelial Cells (HMEC). Jan 2015. https://www. researchgate.net/publication/268226306_Effect_of_aflatoxin_ B1_on_BRCA1_and_BRCA2_genes_expression_under_in_ vitro_cultured_cell_line_of_normal_Human_Mammary_Epithelial Cells HMEC.

3. Bbosa GS, Kitya D, Lubega A, Ogwal-Okeng J, Anokbonggo WW and Kyegombe DB: Review of the biological and health effects of aflatoxins on body organs and body systems. In: Aflatoxins - Recent Advances and Future Prospects. RazzaghiAbyaneh M (ed). InTech. doi: 10.5772/51201.

4. Mohd-Redzwan S, Jamaluddin R, Abd-Mutalib MS and Ahmad Z: A mini review on aflatoxin exposure in Malaysia: Past, present and future. Front Microbiol 4: 334, 2013.

5. El-banna AA, Pitt J and Leistner L: Production of mycotoxins by Penicillium species. Syst Appl Microbiol 10: 42-46, 1987. doi: 10.1016/S0723-2020(87)80008-5.

6. Frisvad JC, Filtenborg $\mathrm{O}$ and Thrane U: Analysis and screening for mycotoxins and other secondary metabolites in fungal cultures by thin-layer chromatography and high-performance liquid chromatography. Arch Environ Contam Toxicol 18: 331-335, 1989.

7. Lin L, Zhang J, Wang P, Wang Y and Chen J: Thin-layer chromatography of mycotoxins and comparison with other chromatographic methods. J Chromatogr A 815: 3-20, 1998.

8. van der Gaag B, Spath S, Dietrich H, Stigter E, Boonzaaijer G, van Osenbruggen $\mathrm{T}$ and Koopal K: Biosensors and multiple mycotoxin analysis. Food Control 14: 251-254, 2003.

9. Butler WH, Greenblatt M and Lijinsky W: Carcinogenesis in rats by aflatoxins B1, G1, and B2. Cancer Res 29: 2206-2211, 1969.

10. Creppy EE: Update of survey, regulation and toxic effects of mycotoxins in Europe. Toxicol Lett 127: 19-28, 2002.

11. Ghoshal AK and Farber E: The induction of liver cancer by dietary deficiency of choline and methionine without added carcinogens. Carcinogenesis 5: 1367-1370, 1984.

12. Kensler TW, Egner PA, Davidson NE, Roebuck BD, Pikul A and Groopman JD: Modulation of aflatoxin metabolism, aflatoxinN7-guanine formation, and hepatic tumorigenesis in rats fed ethoxyquin: Role of induction of glutathione S-transferases. Cancer Res 46: 3924-3931, 1986.

13. Davis ND, Diener UL and Eldridge DW: Production of aflatoxins B1 and G1 by Aspergillus flavus in a semisynthetic medium. Appl Microbiol 14: 378-380, 1966.

14. Dorner JW, Cole RJ and Diener UL: The relationship of Aspergillus flavus and Aspergillus parasiticus with reference to production of aflatoxins and cyclopiazonic acid. Mycopathologia 87: 13-15, 1984. 
15. Farag RS, Daw ZY and Abo-Raya SH: Influence of some spice essential oils on Aspergillus parasiticus growth and production of aflatoxins in a synthetic medium. J Food Sci 54: 74-76, 1989. doi: 10.1111/j.1365-2621.1989.tb08571.x.

16. Mateles RI and Adye JC: Production of aflatoxins in submerged culture. Appl Microbiol 13: 208-211, 1965.

17. Chu FS: Mycotoxins: food contamination, mechanism, carcinogenic potential and preventive measures. Mutat Res 259: 291-306, 1991. doi: 10.1016/0165-1218(91)90124-5.

18. Jelinek CF, Pohland AE and Wood GE: Worldwide occurrence of mycotoxins in foods and feeds - an update. J Assoc Off Anal Chem 72: 223-230, 1989.

19. Krogh P (ed): Mycotoxins in food. Academic Press Ltd., London, 1987.

20. Wang $\mathbf{J}$ and Liu XM: Contamination of aflatoxins in different kinds of foods in China. Biomed Environ Sci 20: 483-487, 2007

21. Rustom IY: Aflatoxin in food and feed: Occurrence, legislation and inactivation by physical methods. Food Chem 59: 57-67, 1997.

22. Tabata S, Kamimura H, Ibe A, Hashimoto H, Iida M, Tamura Y and Nishima T: Aflatoxin contamination in foods and foodstuffs in Tokyo: 1986-1990. J AOAC Int 76: 32-35, 1993.

23. Lane KS: Aflatoxin, tobacco, ammonia and the p53 tumorsuppressor gene: Cancer's missing link? MedGenMed 1: E10, 1999.

24. Hill RA, Blankenship PD, Cole RJ and Sanders TH: Effects of soil moisture and temperature on preharvest invasion of peanuts by the Aspergillus flavus group and subsequent aflatoxin development. Appl Environ Microbiol 45: 628-633, 1983.

25. Desjardins AE: Fusarium mycotoxins: chemistry, genetics, and biology. American Phytopathological Society. APS Press, St. Paul, MN, 2006.

26. Placinta C, D'mello J and Macdonald A: A review of worldwide contamination of cereal grains and animal feed with Fusarium mycotoxins. Anim Feed Sci Technol 78: 21-37, 1999.

27. Richard JL: Some major mycotoxins and their mycotoxicoses an overview. Int J Food Microbiol 119: 3-10, 2007.

28. Gelderblom WC, Jaskiewicz K, Marasas WF, Thiel PG, Horak RM, Vleggaar R and Kriek NP: Fumonisins - novel mycotoxins with cancer-promoting activity produced by Fusarium moniliforme. Appl Environ Microbiol 54: 1806-1811, 1988.

29. Sydenham EW, Shephard GS, Thiel PG, Stockenström S, Snijman PW and Van Schalkwyk DJ: Liquid chromatographic determination of fumonisins B1, B2, and B3 in corn: AOAC-IUPAC Collaborative Study. J AOAC Int 79: 688-696, 1996.

30. Gimeno A: Thin layer chromatographic determination of aflatoxins, ochratoxins, sterigmatocystin, zearalenone, citrinin, T-2 toxin, diacetoxyscirpenol, penicillic acid, patulin, and penitrem A. J Assoc Off Anal Chem 62: 579-585, 1979.

31. Petzinger E and Weidenbach A: Mycotoxins in the food chain: The role of ochratoxins. Livest Prod Sci 76: 245-250, 2002.

32. Trenk HL, Butz ME and Chu FS: Production of ochratoxins in different cereal products by Aspergillus ochraceus. App Microbiol 21: 1032-1035, 1971

33. Cavin C, Delatour T, Marin-Kuan M, Holzhäuser D, Higgins L, Bezençon C, Guignard G, Junod S, Richoz-Payot J, Gremaud E, et al: Reduction in antioxidant defenses may contribute to Ochratoxin A toxicity and carcinogenicity. Toxicol Sci 96: 30-39, 2007.

34. Fink-Gremmels J, Jahn A and Blom MJ: Toxicity and metabolism of Ochratoxin A. Nat Toxins 3: 214-220, discussion 221, 1995.

35. Rahimtula AD, Béréziat J-C, Bussacchini-Griot V and Bartsch H: Lipid peroxidation as a possible cause of Ochratoxin A toxicity. Biochem Pharmacol 37: 4469-4477, 1988.

36. Battilani P, Giorni P and Pietri A: Epidemiology of toxinproducing fungi and Ochratoxin A occurrence in grape. In: Epidemiology of Mycotoxin Producing Fungi. Springer, pp715-722, 2003. doi: 10.1007/978-94-017-1452-5_6.

37. Czerwiecki L, Czajkowska D and Witkowska-Gwiazdowska A: On Ochratoxin A and fungal flora in Polish cereals from conventional and ecological farms. Part 2: Occurrence of Ochratoxin A and fungi in cereals in 1998. Food Addit Contam 19: 1051-1057, 2002.

38. Duarte SC, Pena A and Lino CM: A review on Ochratoxin A occurrence and effects of processing of cereal and cereal derived food products. Food Microbiol 27: 187-198, 2010.

39. Shotwell OL, Hesseltine CW and Goulden ML: Ochratoxin A: Occurrence as natural contaminant of a corn sample. Appl Microbiol 17: 765-766, 1969.
40. López-García R: Mycotoxin management: an international challenge. In: Ensuring Global Food Safety: Exploring Global Harmonization. Boisrobert C, et al (eds). Elsevier, pp209-216, 2009.

41. Bennett JW and Klich M: Mycotoxins. Clin Microbiol Rev 16 497-516, 2003. doi: 10.1128/CMR.16.3.497-516.2003.

42. Squire RA: Ranking animal carcinogens: A proposed regulatory approach. Science 214: 877-880, 1981.

43. Goto T, Wicklow DT and Ito Y: Aflatoxin and cyclopiazonic acid production by a sclerotium-producing Aspergillus tamarii strain. Appl Environ Microbiol 62: 4036-4038, 1996.

44. Klich MA, Mullaney EJ, Daly CB and Cary JW: Molecular and physiological aspects of aflatoxin and sterigmatocystin biosynthesis by Aspergillus tamarii and A. ochraceoroseus. Appl Microbiol Biotechnol 53: 605-609, 2000.

45. Peterson SW, Ito Y, Horn BW and Goto T: Aspergillus bombycis, a new aflatoxigenic species and genetic variation in its sibling species, A. nomius. Mycologia 93: 689-703, 2001.

46. Heathcote JG and Hibbert J: Aflatoxins: Chemical and Biological aspects. Elsevier Scientific Publishing Co., Amsterdam, 1978

47. Bennett JW, Chang PK and Bhatnagar D: One gene to whole pathway: The role of norsolorinic acid in aflatoxin research. Adv Appl Microbiol 45: 1-15, 1997.

48. Cleveland TE and Bhatnagar D: Molecular strategies for reducing aflatoxin levels in crops before harvest. In: Molecular Approaches to Improving Food Quality and Safety. Springer, pp205-228, 1992. doi: 10.1007/978-1-4684-8070-2_9.

49. Hicks JK, Shimizu K and Keller NP: Genetics and biosynthesis of aflatoxins and sterigmatocystin. In: The Mycota XI. Agricultural Applications. Kempken F (ed). Springer-Verlag, Berlin, pp55-69, 2002.

50. Payne GA and Brown MP: Genetics and physiology of aflatoxin biosynthesis. Annu Rev Phytopathol 36: 329-362, 1998.

51. Townsend C: Progress toward a biosynthetic rationale of the aflatoxin pathway. Pure Appl Chem 58: 227-238, 1986.

52. Trail F, Mahanti N and Linz J: Molecular biology of aflatoxin biosynthesis. Microbiology 141: 755-765, 1995.

53. Hackbart H, Prietto L, Primel EG, Garda-Buffon J and Badiale-Furlong E: Simultaneous extraction and detection of Ochratoxin A and citrinin in rice. J Braz Chem Soc 23: 103-109, 2012.

54. Aleo MD, Wyatt RD and Schnellmann RG: The role of altered mitochondrial function in citrinin-induced toxicity to rat renal proximal tubule suspensions. Toxicol Appl Pharmacol 109: 455-463, 1991.

55. Manabe M: Fermented foods and mycotoxins. J Jpn Assoc Mycotoxicol 51: 25-29, 2001

56. Carlton WW and Tuite J: Metabolites of $P$. viridicatum toxicology. In: Mycotoxins in Human and Animal Health. Mehlman MA (ed). Pathotox Publications, Inc., Park Forest South, IL, pp525-555, 1977.

57. Saito M, Enomoto M, Tatsuno $\mathrm{T}$ and Uraguchi K: Yellowed Rice Toxins: Luteoskyrin and Related Compounds, ChlorineContaining Compounds, and Citrinin. Ajl, Samuel J Microb Toxins, 1971 .

58. Richard JL (ed): Mycotoxins - an overview. In: Romer Labs' Guide To Mycotoxins. 2012.

59. Bennett J and Bentley R: Pride and prejudice: The story of ergot. Perspect Biol Med 42: 333-355, 1999.

60. Sweeney MJ and Dobson AD: Molecular biology of mycotoxin biosynthesis. FEMS Microbiol Lett 175: 149-163, 1999.

61. Lia Y, Lou L, Cerny RL, Butchko RA, Proctor RH, Shen Y and Du L: Tricarballylic ester formation during biosynthesis of fumonisin mycotoxins in Fusarium verticillioides. Mycology 4: 179-186, 2013.

62. Van der Merwe KJ, Steyn PS, Fourie L, Scott DB and Theron JJ: Ochratoxin A, a toxic metabolite produced by Aspergillus ochraceus Wilh. Nature 205: 1112-1113, 1965.

63. Huang B, Tao W, Shi J, Tang L and Jin J: Determination of Ochratoxin A by polyclonal antibodies based sensitive timeresolved fluoroimmunoassay. Arch Toxicol 80: 481-485, 2006.

64. Ciegler A, Detroy RW and Lillehoj EB: Patulin, penicillic acid, and other carcinogenic lactones. In: Microbial Toxins. Ciegler A, Kadis S and Ajl SJ (eds). Vol. 6. Academic Press, New York, pp409-434, 1971 .

65. Sekiguchi J and Gaucher GM: Identification of phyllostine as an intermediate of the patulin pathway in Penicillium urticae. Biochemistry 17: 1785-1791, 1978.

66. Cole RJ and Cox RH (eds): The trichothecenes. In: Handbook of Toxic Fungal Metabolites. Academic Press, New York, pp152-263, 1981. 
67. Scott PM: The natural occurrence of trichothecenes. In: Trichothecene mycotoxicosis: Pathophysiologic effects Beasley VR (ed). Vol. 1. CRC Press, Boca Raton, FL, pp1-26, 1989.

68. Ueno Y (ed): Trichothecenes. In: Chemical, Biological and Toxicological Aspects. Elsevier, Amsterdam, 1983.

69. Marasas WFO, Nelson PE and Toussoun TA: Toxigenic Fusarium species. Identity and mycotoxicology. University Park: Pennsylvania State University Press, 1984.

70. Hinkley SF and Jarvis BB: 15 Chromatographic method for Stachybotrys toxins. In: Mycotoxin Protocols. Vol. 157. Humana Press, pp173-194, 2001.

71. Urry W, Wehrmeister H, Hodge E and Hidy P: The structure of zearalenone. Tetrahedron Lett 7: 3109-3114, 1966.

72. Cousin MA, Riley RT and Pestka JJ: Foodborne Mycotoxins: Chemistry, Biology, Ecology, and Toxicology. Caister Academic Press, Norfolk, 2005.

73. Bullerman LB and Bianchini A: Stability of mycotoxins during food processing. Int J Food Microbiol 119: 140-146, 2007.

74. Visconti A and Pascale M: REVIEW: An overview on Fusarium mycotoxins in the durum wheat pasta production chain. Cereal Chem 87: 21-27, 2010.

75. Kabak B: The fate of mycotoxins during thermal food processing. J Sci Food Agric 89: 549-554, 2009.

76. Scott P: Effects of food processing on mycotoxins. J Food Prot 47: 489-499, 1984

77. Doyle M, Applebaum R, Brackett R and Marth E: Physical, chemical and biological degradation of mycotoxins in foods and agricultural commodities. J Food Prot 45: 964-971, 1982.

78. Lauren DR and Smith WA: Stability of the fusarium mycotoxins nivalenol, deoxynivalenol and zearalenone in ground maize under typical cooking environments. Food Addit Contam 18: 1011-1016, 2001.

79. Gund P: Guanidine, trimethylenemethane, and Y-delocalization. Can acyclic compounds have aromatic stability? J Chem Educ 49: 100, 1972.

80. Silverstein RM and Bassler GC: Spectrometric identification of organic compounds. J Chem Educ 39: 546, 1962.

81. Abbas HK (ed): Aflatoxin and Food Safety. CRC Press, 2005. doi: 10.1201/9781420028171.

82. Jarvis BB and Miller JD: Mycotoxins as harmful indoor air contaminants. Appl Microbiol Biotechnol 66: 367-372, 2005.

83. Serra R, Braga A and Venâncio A: Mycotoxin-producing and other fungi isolated from grapes for wine production, with particular emphasis on Ochratoxin A. Res Microbiol 156 : 515-521, 2005

84. Agag B: Mycotoxins in foods and feeds: 1-aflatoxins. Assiut Univ Bull Environ Res 7: 173-205, 2004.

85. Eaton DL and Groopman JD (eds): Toxicology of Aflatoxins: Human Health, Veterinary, and Agricultural Significance. Elsevier, 2013

86. He XY, Tang L, Wang SL, Cai QS, Wang JS and Hong JY: Efficient activation of aflatoxin B1 by cytochrome P450 2A13, an enzyme predominantly expressed in human respiratory tract. Int J Cancer 118: 2665-2671, 2006.

87. Baertschi SW, Raney KD, Stone MP and Harris TM: Preparation of the 8,9-epoxide of the mycotoxin aflatoxin B1: The ultimate carcinogenic species. J Am Chem Soc 110: 7929-7931, 1988.

88. Yates MS, Kwak M-K, Egner PA, Groopman JD, Bodreddigari S, Sutter TR, Baumgartner KJ, Roebuck BD, Liby KT, Yore MM, et al: Potent protection against aflatoxin-induced tumorigenesis through induction of Nrf2-regulated pathways by the triterpenoid 1-[2-cyano-3-,12-dioxooleana-1,9(11)-dien-28-oyl] imidazole. Cancer Res 66: 2488-2494, 2006.

89. Boorman GA, McDonald MR, Imoto S and Persing R: Renal lesions induced by Ochratoxin A exposure in the F344 rat. Toxicol Pathol 20: 236-245, 1992.

90. Chu Y-M, Jeon J-J, Yea S-J, Kim Y-H, Yun S-H, Lee Y-W and Kim KH: Double-stranded RNA mycovirus from Fusarium graminearum. Appl Environ Microbiol 68: 2529-2534, 2002.

91. Kuiper-Goodman T and Scott PM: Risk assessment of the mycotoxin Ochratoxin A. Biomed Environ Sci 2: 179-248, 1989.

92. Bunge I, Heller K and Röschenthaler R: Isolation and purification of Ochratoxin A. Zeitschrift für Lebensmitteluntersuchung undForschung 168: 457-458, 1979. doi: 10.1007/BF01479260

93. Marquardt RR and Frohlich AA: A review of recent advances in understanding ochratoxicosis. J Anim Sci 70: 3968-3988, 1992.

94. Meisner H and Meisner P: Ochratoxin A, an in vivo inhibitor of renal phosphoenolpyruvate carboxykinase. Arch Biochem Biophys 208: 146-153, 1981.
95. Rocha O, Ansari K and Doohan FM: Effects of trichothecene mycotoxins on eukaryotic cells: A review. Food Addit Contam 22: 369-378, 2005.

96. Desmond OJ, Manners JM, Stephens AE, Maclean DJ, Schenk PM, Gardiner DM, Munn AL and Kazan K: The Fusarium mycotoxin deoxynivalenol elicits hydrogen peroxide production, programmed cell death and defence responses in wheat. Mol Plant Pathol 9: 435-445, 2008.

97. Pestka JJ: Deoxynivalenol-induced IgA production and IgA nephropathy-aberrant mucosal immune response with systemic repercussions. Toxicol Lett 140-141: 287-295, 2003.

98. Bunner DL and Morris ER: Alteration of multiple cell membrane functions in L-6 myoblasts by T-2 toxin: An important mechanism of action. Toxicol Appl Pharmacol 92: 113-121, 1988

99. Diamond M, Reape TJ, Rocha O, Doyle SM, Kacprzyk J, Doohan FM and McCabe PF: The fusarium mycotoxin deoxynivalenol can inhibit plant apoptosis-like programmed cell death. PLoS One 8: e69542, 2013.

100. Hansen B: Inhibition of protein synthesis by trichothecenes. In: Mycotoxins in Human and Animal Health. Meky FA, Hardie LJ, Evans SW, Wild CP (eds). Pathotox Publications, Park Forest South, IL, pp263-273, 2001.

101. Thompson WL and Wannemacher RW Jr: Detection and quantitation of T-2 mycotoxin with a simplified protein synthesis inhibition assay. Appl Environ Microbiol 48: 1176-1180, 1984.

102. Wannemacher RW, Wiener SL, Sidell FR, Takafuji ET and Franz DR: Trichothecene mycotoxins. In: Medical Aspects of Chemical and Biological Warfare. pp655-676, 1997.

103. Yang G-H, Jarvis BB, Chung Y-J and Pestka JJ: Apoptosis induction by the satratoxins and other trichothecene mycotoxins: Relationship to ERK, p38 MAPK, and SAPK/JNK activation. Toxicol Appl Pharmacol 164: 149-160, 2000.

104. Zhou H-R, Islam Z and Pestka JJ: Rapid, sequential activation of mitogen-activated protein kinases and transcription factors precedes proinflammatory cytokine mRNA expression in spleens of mice exposed to the trichothecene vomitoxin. Toxicol Sci 72: 130-142, 2003.

105. Sansing GA, Lillehoj EB, Detroy RW and Miller MA: Synergistic toxic effects of citrinin, Ochratoxin A and penicillic acid in mice. Toxicon 14: 213-220, 1976.

106. Wichmann G, Herbarth $\mathrm{O}$ and Lehmann I: The mycotoxins citrinin, gliotoxin, and patulin affect interferon- $\gamma$ rather than interleukin-4 production in human blood cells. Environ Toxicol 17: 211-218, 2002

107. Dönmez-Altuntas H, Dumlupinar G, Imamoglu N, Hamurcu Z and Liman BC: Effects of the mycotoxin citrinin on micronucleus formation in a cytokinesis-block genotoxicity assay in cultured human lymphocytes. J Appl Toxicol 27: 337-341, 2007.

108. Flajs D and Peraica M: Toxicological properties of citrinin. Arh Hig Rada Toksikol 60: 457-464, 2009.

109. Bhat R, Rai RV and Karim AA: Mycotoxins in food and feed: present status and future concerns. Compr Rev Food Sci Food Saf 9: 57-81, 2010. doi: 10.1111/j.1541-4337.2009.00094.x.

110. Matossian MK: Mold poisoning: An unrecognized English health problem, 1550-1800. Med Hist 25: 73-84, 1981.

111. Matossian MK: Poisons of the Past: Molds, Epidemics, and History. Yale University Press, New Haven and London, 1989. Arch Nat Hist 18: 145. Available online: Jul 2010. doi: http:// dx.doi.org/10.3366/anh.1991.18.1.145.

112. Binder EM: Managing the risk of mycotoxins in modern feed production. Anim Feed Sci Technol 133: 149-166, 2007.

113. Lorenz K and Hoseney RC: Ergot on cereal grains. Crit Rev Food Sci Nutr 11: 311-354, 1979.

114. Riddle JM: Eve's Herbs: A History of Contraception and Abortion in the West. Harvard University Press, 1999.

115. Caballero-Granado FJ, Viciana P, Cordero E, Gómez-Vera MJ, del Nozal M and López-Cortés LF: Ergotism related to concurrent administration of ergotamine tartrate and ritonavir in an AIDS patient. Antimicrob Agents Chemother 41: 1207, 1997.

116. Alberts JF, Gelderblom WC, Thiel PG, Marasas WF Van Schalkwyk DJ and Behrend Y: Effects of temperature and incubation period on production of fumonisin B1 by Fusarium moniliforme. Appl Environ Microbiol 56: 1729-1733, 1990.

117. Gelderblom WC, Smuts CM, Abel S, Snyman SD, Cawood ME, van der Westhuizen L and Swanevelder S: Effect of fumonisin B1 on protein and lipid synthesis in primary rat hepatocytes. Food Chem Toxicol 34: 361-369, 1996. 
118. Pozzi CR, Corrêa B, Xavier JG, Direito GM, Orsi RB and Matarazzo SV: Effects of prolonged oral administration of fumonisin B1 and aflatoxin B1 in rats. Mycopathologia 151: 21-27, 2001

119. Sydenham EW, Shephard GS, Thiel PG, Marasas WF and Stockenstrom S: Fumonisin contamination of commercial cornbased human foodstuffs. J Agric Food Chem 39: 2014-2018, 1991.

120. Kouadio JH, Mobio TA, Baudrimont I, Moukha S, Dano SD and Creppy EE: Comparative study of cytotoxicity and oxidative stress induced by deoxynivalenol, zearalenone or fumonisin B1 in human intestinal cell line Caco-2. Toxicology 213: 56-65, 2005.

121. Tolleson WH, Melchior WB Jr, Morris SM, McGarrity LJ, Domon OE, Muskhelishvili L, James SJ and Howard PC: Apoptotic and anti-proliferative effects of fumonisin B1 in human keratinocytes, fibroblasts, esophageal epithelial cells and hepatoma cells. Carcinogenesis 17: 239-249, 1996.

122. Hendricks KA, Simpson JS and Larsen RD: Neural tube defects along the Texas-Mexico border, 1993-1995. Am J Epidemiol 149: 1119-1127, 1999.

123. Missmer S, Hendricks K, Suarez L, Larsen R and Rothman I: Fumonisins and neural tube defects. Epidemiology 11: 183-184, 2000.

124. Rheeder JP, Marasas WF and Vismer HF: Production of fumonisin analogs by Fusarium species. Appl Environ Microbiol 68: 2101-2105, 2002.

125. Trucksess MW and Tang Y: Solid-phase extraction method for patulin in apple juice and unfiltered apple juice. J AOAC Int 82: 1109-1113, 1999.

126. Stafford ME and McLaughlin CS: Trichodermin, a possible inhibitor of the termination process of protein synthesis. J Cell Physiol 82: 121-128, 1973.

127. Wei C-M, Campbell IM, McLaughlin CS and Vaughan MH: Letter: Binding of trichodermin to mammalian ribosomes and its inhibition by other 12,13-epoxytrichothecenes. Mol Cell Biochem 3: 215-219, 1974.

128. Bennett JW and Klich M: Mycotoxins. Clin Microbiol Rev 16: 497-516, 2003.

129. Rotter BA: Invited review: Toxicology of deoxynivalenol (vomitoxin). J Toxicol Environ Health A 48: 1-34, 1996.

130. Islam Z, Gray JS and Pestka JJ: p38 Mitogen-activated protein kinase mediates IL- 8 induction by the ribotoxin deoxynivalenol in human monocytes. Toxicol Appl Pharmacol 213: 235-244, 2006.

131.Zain ME: Impact of mycotoxins on humans and animals. J Saudi Chem Soc 15: 129-144, 2011.

132. Ueno Y, Umemori K, Niimi E, Tanuma S, Nagata S, Sugamata M, Ihara T, Sekijima M, Kawai K, Ueno I, et al: Induction of apoptosis by T-2 toxin and other natural toxins in HL-60 human promyelotic leukemia cells. Nat Toxins 3: 129-137, 1995.

133. Yarom R, More R, Eldor A and Yagen B: The effect of T-2 toxin on human platelets. Toxicol Appl Pharmacol 73: 210-217, 1984.

134. Sudakin DL: Trichothecenes in the environment: Relevance to human health. Toxicol Lett 143: 97-107, 2003.

135.Lautraite S, Parent-Massin D, Rio B and Hoellinger $\mathrm{H}$ Comparison of toxicity induced by T-2 toxin on human and rat granulo-monocytic progenitors with an in vitro model. Hum Exp Toxicol 14: 672-678, 1995.

136. Kuhn DM and Ghannoum MA: Indoor mold, toxigenic fungi, and Stachybotrys chartarum: Infectious disease perspective. Clin Microbiol Rev 16: 144-172, 2003.

137. Kuiper-Goodman T, Scott PM and Watanabe H: Risk assessment of the mycotoxin zearalenone. Regul Toxicol Pharmacol 7: 253-306, 1987.

138. Utian WH: Comparative trial of P1496, a new non-steroidal oestrogen analogue. BMJ 1: 579-581, 1973.

139. Shier WT, Shier AC, Xie W and Mirocha CJ: Structure-activity relationships for human estrogenic activity in zearalenone mycotoxins. Toxicon 39: 1435-1438, 2001.

140. Kanora A and Maes D: The role of mycotoxins in pig reproduction: a review. Vet Med Czech 54: 565-576, 2009.

141. Ueno Y and Kubota K: DNA-attacking ability of carcinogenic mycotoxins in recombination-deficient mutant cells of Bacillus subtilis. Cancer Res 36: 445-451, 1976.

142.Uraguchi K, Saito M, Noguchi Y, Takahashi K, Enomoto M and Tatsuno T: Chronic toxicity and carcinogenicity in mice of the purified mycotoxins, luteoskyrin and cyclochlorotine. Food Cosmet Toxicol 10: 193-207, 1972.
143. Voss KA, Howard PC, Riley RT, Sharma RP, Bucci TJ and Lorentzen RJ: Carcinogenicity and mechanism of action of fumonisin B1: A mycotoxin produced by Fusarium moniliforme (=F. verticillioides). Cancer Detect Prev 26: 1-9, 2002.

144. Mori H, Kawai K, Ohbayashi F, Kuniyasu T, Yamazaki M, Hamasaki T and Williams GM: Genotoxicity of a variety of mycotoxins in the hepatocyte primary culture/DNA repair test using rat and mouse hepatocytes. Cancer Res 44: 2918-2923, 1984.

145. Newberne PM: Mycotoxins: Toxicity, carcinogenicity, and the influence of various nutritional conditions. Environ Health Perspect 9: 1-32, 1974.

146. Gradelet S, Astorg P, Le Bon A-M, Bergès R and Suschetet M: Modulation of aflatoxin B1 carcinogenicity, genotoxicity and metabolism in rat liver by dietary carotenoids: Evidence for a protective effect of CYP1A inducers. Cancer Lett 114: 221-223, 1997.

147. Massey TE, Stewart RK, Daniels JM and Liu L: Biochemical and molecular aspects of mammalian susceptibility to aflatoxin B1 carcinogenicity. Proc Soc Exp Biol Med 208: 213-227, 1995.

148. Iyer RS, Coles BF, Raney KD, Thier R, Guengerich FP and Harris TM: DNA adduction by the potent carcinogen aflatoxin B1: Mechanistic studies. J Am Chem Soc 116: 1603-1609, 1994.

149. Johnson WW and Guengerich FP: Reaction of aflatoxin B1 exo8,9-epoxide with DNA: Kinetic analysis of covalent binding and DNA-induced hydrolysis. Proc Natl Acad Sci USA 94: 6121-6125, 1997

150. Wilson SC, Howard PW, Forrow SM, Hartley JA, Adams LJ, Jenkins TC, Kelland LR and Thurston DE: Design, synthesis, and evaluation of a novel sequence-selective epoxide-containing DNA cross-linking agent based on the pyrrolo[2,1-c][1,4]benzodiazepine system. J Med Chem 42: 4028-4041, 1999.

151.Hollstein M, Sidransky D, Vogelstein B and Harris CC: p53 mutations in human cancers. Science 253: 49-53, 1991.

152. Chen J, Goetchius MP, Campbell TC and Combs GF Jr: Effects of dietary selenium and vitamin $\mathrm{E}$ on hepatic mixed-function oxidase activities and in vivo covalent binding of aflatoxin B1 in rats. J Nutr 112: 324-331, 1982.

153. Peers FG and Linsell CA: Dietary aflatoxins and liver cancer - a population based study in Kenya. Br J Cancer 27: 473-484, 1973.

154. Aguilar F, Hussain SP and Cerutti P: Aflatoxin B1 induces the transversion of G-->T in codon 249 of the $\mathrm{p} 53$ tumor suppressor gene in human hepatocytes. Proc Natl Acad Sci USA 90: 8586-8590, 1993.

155. Van Rensburg SJ, Cook-Mozaffari P, Van Schalkwyk DJ, Van der Watt JJ, Vincent TJ and Purchase IF: Hepatocellular carcinoma and dietary aflatoxin in Mozambique and Transkei. Br J Cancer 51: 713-726, 1985.

156. Sun G, Wang S, Hu X, Su J, Huang T, Yu J, Tang L, Gao W and Wang JS: Fumonisin B1 contamination of home-grown corn in high-risk areas for esophageal and liver cancer in China. Food Addit Contam 24: 181-185, 2007.

157. Kelly JD, Eaton DL, Guengerich FP and Coulombe RA Jr: Aflatoxin B1 activation in human lung. Toxicol Appl Pharmacol 144: 88-95, 1997.

158. Divine KK, Gilliland FD, Crowell RE, Stidley CA, Bocklage TJ, Cook DL and Belinsky SA: The XRCC1 399 glutamine allele is a risk factor for adenocarcinoma of the lung. Mutat Res 461: 273-278, 2001

159. Dvorackova I, Stora C and Ayraud N: Evidence of aflatoxin B1 in two cases of lung cancer in man. J Cancer Res Clin Oncol 100: 221-224, 1981.

160. Zhang X, Miao X, Liang G, Hao B, Wang Y, Tan W, Li Y, Guo Y, He F, Wei Q, et al: Polymorphisms in DNA base excision repair genes ADPRT and XRCC1 and risk of lung cancer. Cancer Res 65: 722-726, 2005.

161. Ketterer B, Harris JM, Talaska G, Meyer DJ, Pemble SE, Taylor JB, Lang NP and Kadlubar FF: The human glutathione S-transferase supergene family, its polymorphism, and its effects on susceptibility to lung cancer. Environ Health Perspect 98: 87-94, 1992.

162. Marin-Kuan M, Nestler S, Verguet C, Bezençon C, Piguet D, Mansourian R, Holzwarth J, Grigorov M, Delatour T, Mantle P, et al: A toxicogenomics approach to identify new plausible epigenetic mechanisms of Ochratoxin A carcinogenicity in rat. Toxicol Sci 89: 120-134, 2006.

163. Marin-Kuan M, Cavin C, Delatour T and Schilter B: Ochratoxin A carcinogenicity involves a complex network of epigenetic mechanisms. Toxicon 52: 195-202, 2008 
164.Dörrenhaus A, Flieger A, Golka K, Schulze H, Albrecht M, Degen GH and Föllmann W: Induction of unscheduled DNA synthesis in primary human urothelial cells by the mycotoxin Ochratoxin A. Toxicol Sci 53: 271-277, 2000.

165. Boesch-Saadatmandi C, Loboda A, Jozkowicz A, Huebbe P, Blank R, Wolffram S, Dulak J and Rimbach G: Effect of Ochratoxin A on redox-regulated transcription factors, antioxidant enzymes and glutathione-S-transferase in cultured kidney tubulus cells. Food Chem Toxicol 46: 2665-2671, 2008.

166.Pfohl-Leszkowicz A and Manderville RA: An update on direct genotoxicity as a molecular mechanism of Ochratoxin A carcinogenicity. Chem Res Toxicol 25: 252-262, 2012.

167. Adler M, Müller K, Rached E, Dekant W and Mally A: Modulation of key regulators of mitosis linked to chromosomal instability is an early event in Ochratoxin A carcinogenicity. Carcinogenesis 30: 711-719, 2009

168.González-Salgado A, Patiño B, Vázquez C and González-Jaén MT: Discrimination of Aspergillus niger and other Aspergillus species belonging to section Nigri by PCR assays. FEMS Microbiol Lett 245: 353-361, 2005.

169.Lioi MB, Santoro A, Barbieri R, Salzano S and Ursini MV: Ochratoxin A and zearalenone: A comparative study on genotoxic effects and cell death induced in bovine lymphocytes. Mutat Res 557: 19-27, 2004.

170.Pfohl-Leszkowicz A and Manderville RA: Ochratoxin A: An overview on toxicity and carcinogenicity in animals and humans. Mol Nutr Food Res 51: 61-99, 2007.

171. Marin-Kuan M, Nestler S, Verguet C, Bezençon C, Piguet D, Delatour T, Mantle P, Cavin C and Schilter B: MAPK-ERK activation in kidney of male rats chronically fed Ochratoxin A at a dose causing a significant incidence of renal carcinoma. Toxicol Appl Pharmacol 224: 174-181, 2007.

172.Dunnick JK, Elwell MR, Huff J and Barrett JC: Chemically induced mammary gland cancer in the National Toxicology Program's carcinogenesis bioassay. Carcinogenesis 16: 173-179, 1995.

173. Bray F, Ferlay J, Devesa SS, McGlynn KA and Møller H: Interpreting the international trends in testicular seminoma and nonseminoma incidence. Nat Clin Pract Urol 3: 532-543, 2006.

174. Jennings-Gee JE, Tozlovanu M, Manderville R, Miller MS Pfohl-Leszkowicz A and Schwartz GG: Ochratoxin A: In utero exposure in mice induces adducts in testicular DNA. Toxins (Basel) 2: 1428-1444, 2010.

175. Schwartz GG: Hypothesis: Does Ochratoxin A cause testicular cancer? Cancer Causes Control 13: 91-100, 2002.

176. Vrabcheva T, Usleber E, Dietrich R and Märtlbauer E: Co-occurrence of Ochratoxin A and citrinin in cereals from Bulgarian villages with a history of Balkan endemic nephropathy. J Agric Food Chem 48: 2483-2488, 2000.

177. Knasmüller S, Cavin C, Chakraborty A, Darroudi F, Majer BJ, Huber WW and Ehrlich VA: Structurally related mycotoxins Ochratoxin A, ochratoxin B, and citrinin differ in their genotoxic activities and in their mode of action in human-derived liver (HepG2) cells: Implications for risk assessment. Nutr Cancer 50: 190-197, 2004.

178. Thust R and Kneist S: Activity of citrinin metabolized by rat and human microsome fractions in clastogenicity and SCE assays on Chinese hamster V79-E cells. Mutat Res 67: 321-330, 1979.

179. Ostry V, Malir F and Ruprich J: Producers and important dietary sources of Ochratoxin A and citrinin. Toxins (Basel) 5: 1574-1586, 2013.

180. Bouslimi A, Bouaziz C, Ayed-Boussema I, Hassen W and Bacha $\mathrm{H}$ : Individual and combined effects of Ochratoxin $\mathrm{A}$ and citrinin on viability and DNA fragmentation in cultured Vero cells and on chromosome aberrations in mice bone marrow cells. Toxicology 251: 1-7, 2008

181.Pfeiffer E, Gross K and Metzler M: Aneuploidogenic and clastogenic potential of the mycotoxins citrinin and patulin. Carcinogenesis 19: 1313-1318, 1998.

182. Castegnaro M, Chernozemsky IN, Hietanen E and Bartsch H: Are mycotoxins risk factors for endemic nephropathy and associated urothelial cancers? Arch Geschwulstforsch 60: 295-303, 1990.

183. Fink-Gremmels J: Mycotoxins: Their implications for human and animal health. Vet Q 21: 115-120, 1999.

184. Gelderblom WC, Kriek NP, Marasas WF and Thiel PG: Toxicity and carcinogenicity of the Fusarium moniliforme metabolite, fumonisin B1, in rats. Carcinogenesis 12: 1247-1251, 1991.
185. Howard PC, Eppley RM, Stack ME, Warbritton A, Voss KA, Lorentzen RJ, Kovach RM and Bucci TJ: Fumonisin b1 carcinogenicity in a two-year feeding study using F344 rats and B6C3F1 mice. Environ Health Perspect 109 (Suppl 2): 277-282, 2001.

186. Riley RT, Wang E, Schroeder JJ, Smith ER, Plattner RD, Abbas H, Yoo HS and Merrill AH Jr: Evidence for disruption of sphingolipid metabolism as a contributing factor in the toxicity and carcinogenicity of fumonisins. Nat Toxins 4: 3-15, 1996.

187. Chu FS and Li GY: Simultaneous occurrence of fumonisin B1 and other mycotoxins in moldy corn collected from the People's Republic of China in regions with high incidences of esophageal cancer. Appl Environ Microbiol 60: 847-852, 1994.

188. Huang C, Dickman M, Henderson G and Jones C: Repression of protein kinase $\mathrm{C}$ and stimulation of cyclic AMP response elements by fumonisin, a fungal encoded toxin which is a carcinogen. Cancer Res 55: 1655-1659, 1995.

189. Dragan YP, Bidlack WR, Cohen SM, Goldsworthy TL, Hard GC, Howard PC, Riley RT and Voss KA: Implications of apoptosis for toxicity, carcinogenicity, and risk assessment: Fumonisin $\mathrm{B}(1)$ as an example. Toxicol Sci 61: 6-17, 2001.

190. Hendricks K: Fumonisins and neural tube defects in South Texas. Epidemiology 10: 198-200, 1999.

191. Chang P-K, Cary JW, Yu J, Bhatnagar D and Cleveland TE: The Aspergillus parasiticus polyketide synthase gene pksA, a homolog of Aspergillus nidulans $\mathrm{wA}$, is required for aflatoxin $\mathrm{B} 1$ biosynthesis. Mol Gen Genet 248: 270-277, 1995.

192. Gaucher GM: Mycotoxins-their biosynthesis in fungi: Patulin and related carcinogenic lactones. J Food Prot 42: 810-814, 1979.

193. Schumacher DM, Metzler M and Lehmann L: Mutagenicity of the mycotoxin patulin in cultured Chinese hamster V79 cells, and its modulation by intracellular glutathione. Arch Toxicol 79: $110-121,2005$.

194. Stewart SG: Carcinogenesis: A broad critique. J Clin Pathol 21: $534,1968$.

195. Dickens F and Jones HE: Carcinogenic activity of a series of reactive lactones and related substances. Br J Cancer 15: 85-100, 1961.

196. Dickens F and Jones HE: The carcinogenic action of aflatoxin after its subcutaneous injection in the rat. Br J Cancer 17: 691-698, 1963

197. Osswald H, Frank HK, Komitowski D and Winter H: Long-term testing of patulin administered orally to Sprague-Dawley rats and Swiss mice. Food Cosmet Toxicol 16: 243-247, 1978.

198. Mahfoud R, Maresca M, Garmy N and Fantini J: The mycotoxin patulin alters the barrier function of the intestinal epithelium: Mechanism of action of the toxin and protective effects of glutathione. Toxicol Appl Pharmacol 181: 209-218, 2002.

199. Lee KS and Röschenthaler RJ: DNA-damaging activity of patulin in Escherichia coli. Appl Environ Microbiol 52: 1046-1054, 1986

200. Ueno Y, Kubota K, Ito T and Nakamura Y: Mutagenicity of carcinogenic mycotoxins in Salmonella typhimurium. Cancer Res 38: 536-542, 1978

201. Schoental R: Trichothecenes, zearalenone, and other carcinogenic metabolites of Fusarium and related microfungi. Adv Cancer Res 45: 217-290, 1985.

202. Ueno Y: Toxicological features of T-2 toxin and related trichothecenes. Fundam Appl Toxicol 4: S124-S132, 1984.

203. Ueno Y, Yabe T, Hashimoto H, Sekijima M, Masuda T, Kim DJ, Hasegawa R and Ito N: Enhancement of GST-P-positive liver cell foci development by nivalenol, a trichothecene mycotoxin. Carcinogenesis 13: 787-791, 1992.

204. Lafarge-Frayssinet C, Decloitre F, Mousset S, Martin M and Frayssinet C: Induction of DNA single-strand breaks by $\mathrm{T}_{2}$ toxin, a trichothecene metabolite of Fusarium: Effect on lymphoid organs and liver. Mutat Res Genet Toxicol 88: 115-123, 1981

205. Schothorst RC and van Egmond HP: Report from SCOOP task 3.2.10 "collection of occurrence data of Fusarium toxins in food and assessment of dietary intake by the population of EU member states'. Subtask: trichothecenes. Subtask: Trichothecenes. Toxicol Lett 153: 133-143, 2004.

206. Eriksen GS and Pettersson H: Toxicological evaluation of trichothecenes in animal feed. Anim Feed Sci Technol 114: 205-239, 2004.

207. Pestka JJ: Deoxynivalenol: Toxicity, mechanisms and animal health risks. Anim Feed Sci Technol 137: 283-298, 2007.

208. Yazar S and Omurtag GZ: Fumonisins, trichothecenes and zearalenone in cereals. Int J Mol Sci 9: 2062-2090, 2008. 
209. Ryu J-C, Ohtsubo K, Izumiyama N, Nakamura K, Tanaka T, Yamamura $\mathrm{H}$ and Ueno $\mathrm{Y}$ : The acute and chronic toxicities of nivalenol in mice. Fundam Appl Toxicol 11: 38-47, 1988.

210. Bony S, Olivier-Loiseau L, Carcelen M and Devaux A: Genotoxic potential associated with low levels of the Fusarium mycotoxins nivalenol and fusarenon $\mathrm{X}$ in a human intestinal cell line. Toxicol In Vitro 21: 457-465, 2007.

211. Thuvander A, Wikman C and Gadhasson I: In vitro exposure of human lymphocytes to trichothecenes: Individual variation in sensitivity and effects of combined exposure on lymphocyte function. Food Chem Toxicol 37: 639-648, 1999.

212. Craddock VM, Hill RJ and Henderson AR: Stimulation of DNA replication in rat esophagus and stomach by the trichothecene mycotoxin diacetoxyscirpenol. Cancer Lett 38: 199-208, 1987.

213. Wijnands LM and van Leusden FM: An overview of adverse health effects caused by mycotoxins and bioassays for their detection. Research for man and environment. RIVM report 257852,004 2000. http://rivm.openrepository.com/rivm/bitstre $\mathrm{am} / 10029 / 9410 / 1 / 257852004 . p d f$.

214. Bony S, Olivier-Loiseau L, Carcelen M and Devaux A: Genotoxic potential associated with low levels of the Fusarium mycotoxins nivalenol and fusarenon $\mathrm{X}$ in a human intestinal cell line. Toxicol In Vitro 21: 457-465, 2007.

215. Miura K, Aminova L and Murayama Y: Fusarenon-X induced apoptosis in HL-60 cells depends on caspase activation and cytochrome c release. Toxicology 172: 103-112, 2002.

216. Bondy GS, McCormick SP, Beremand MN and Pestka JJ: Murine lymphocyte proliferation impaired by substituted neosolaniols and calonectrins - Fusarium metabolites associated with trichothecene biosynthesis. Toxicon 29: 1107-1113, 1991.

217. Carter CJ and Cannon M: Inhibition of eukaryotic ribosomal function by the sesquiterpenoid antibiotic fusarenon-X. Eur J Biochem 84: 103-111, 1978.

218. Moss MO: Mycotoxin review-2. Fusarium. Mycologist 16: $158-161,2002$.

219. Yazar S and Omurtag GZ: Fumonisins, trichothecenes and zearalenone in cereals. Int J Mol Sci 9: 2062-2090, 2008.

220. Marasas WF, van Rensburg SJ and Mirocha CJ: Incidence of Fusarium species and the mycotoxins, deoxynivalenol and zearalenone, in corn produced in esophageal cancer areas in Transkei. J Agric Food Chem 27: 1108-1112, 1979.

221. Richard JL: Some major mycotoxins and their mycotoxicoses An overview. Int J Food Microbiol 119: 3-10, 2007.

222. Schoental R and Cavanagh JB: Mechanisms involved in the 'dying-back' process - an hypothesis implicating coenzymes. Neuropathol Appl Neurobiol 3: 145-157, 1977.

223. Schoental R and Joffe AZ: Lesions induced in rodents by extracts from cultures of Fusarium poae and F. sporotrichioides. J Pathol 112: 37-42, 1974.

224. Schoental R, Joffe AZ and Yagen B: Irreversible depigmentation of dark mouse hair by T-2 toxin (a metabolite of Fusarium sporotrichioides) and by calcium pantothenate. Experientia 34 763-764, 1978.

225. Ouanes Z, Abid S, Ayed I, Anane R, Mobio T, Creppy EE and Bacha $\mathrm{H}$ : Induction of micronuclei by Zearalenone in vero monkey kidney cells and in bone marrow cells of mice: Protective effect of Vitamin E. Mutat Res 538: 63-70, 2003.

226. Schoental R: Letter: Role of podophyllotoxin in the bedding and dietary zearalenone on incidence of spontaneous tumors in laboratory animals. Cancer Res 34: 2419-2420, 1974
227.Pfohl-Leszkowicz A, Chekir-Ghedira $\mathrm{L}$ and Bacha $\mathrm{H}$ : Genotoxicity of zearalenone, an estrogenic mycotoxin: DNA adduct formation in female mouse tissues. Carcinogenesis 16: 2315-2320, 1995.

228. Program NT; National Toxicology Program: Carcinogenesis Bioassay of Zearalenone (CAS No. 17924-92-4) in F344/N Rats and B6C3F1 Mice (Feed Study). Natl Toxicol Program Tech Rep Ser 235: 1-155, 1982.

229. Cho S-H, Lee C-H, Jang M-R, Son Y-W, Lee S-M, Choi I-S, Kim S and Kim D: Aflatoxins contamination in spices and processed spice products commercialized in Korea. Food Chem 107: 1283-1288, 2008.

230. Samson RA, van Reenen-Hoekstra ES and Van Oorschot CAN: Introduction to food-borne fungi. Centraalbureau voor Schimmelcultures, Institute of the Royal Netherlands Academy of Arts and Sciences, 1981.

231. Jürgen R: Mycotoxins in foodstuffs. Appl Microbiol Biotechnol 1: 183-190, 1975.

232. van Egmond HP, Schothorst RC and Jonker MA: Regulations relating to mycotoxins in food: Perspectives in a global and European context. Anal Bioanal Chem 389: 147-157, 2007.

233. Binder EM: Managing the risk of mycotoxins in modern feed production. Anim Feed Sci Technol 133: 149-166, 2007.

234. Paterson RRM and Lima N: How will climate change affect mycotoxins in food? Food Res Int 43: 1902-1914, 2010.

235. Beckeman M and Skjöldebrand C: Clusters/networks promote food innovations. J Food Eng 79: 1418-1425, 2007.

236. Wansink B: Changing eating habits on the home front: Lost lessons from World War II research. J Public Policy Mark 21: 90-99, 2002

237. Kabak B, Dobson AD and Var I: Strategies to prevent mycotoxin contamination of food and animal feed: A review. Crit Rev Food Sci Nutr 46: 593-619, 2006.

238. Magan N and Aldred D: Post-harvest control strategies: Minimizing mycotoxins in the food chain. Int J Food Microbiol 119: 131-139, 2007.

239. Bergström R, Adami H-O, Möhner M, Zatonski W, Storm H, Ekbom A, Tretli S, Teppo L, Akre O and Hakulinen T: Increase in testicular cancer incidence in six European countries: A birth cohort phenomenon. J Natl Cancer Inst 88: 727-733, 1996.

240. Blot WJ, Harrington JM, Toledo A, Hoover R, Heath CW Jr and Fraumeni JF Jr: Lung cancer after employment in shipyards during World War II. N Engl J Med 299: 620-624, 1978.

241. Tretli S and Gaard M: Lifestyle changes during adolescence and risk of breast cancer: An ecologic study of the effect of World War II in Norway. Cancer Causes Control 7: 507-512, 1996.

242. Birner P, Oberhuber G, Stani J, Reithofer C, Samonigg H, Hausmaninger $\mathrm{H}$, Kubista E, Kwasny W, KandiolerEckersberger D, Gnant M, et al; Austrian Breast \& Colorectal Cancer Study Group: Evaluation of the United States Food and Drug Administration-approved scoring and test system of HER-2 protein expression in breast cancer. Clin Cancer Res 7: 1669-1675, 2001.

243. Lu SH, Hsieh LL, Luo FC and Weinstein IB: Amplification of the EGF receptor and c-myc genes in human esophageal cancers. Int J Cancer 42: 502-505, 1988.

244. Ross JS, Slodkowska EA, Symmans WF, Pusztai L, Ravdin PM and Hortobagyi GN: The HER-2 receptor and breast cancer: Ten years of targeted anti-HER-2 therapy and personalized medicine. Oncologist 14: 320-368, 2009. 